\title{
Subthermocline and Intermediate Zonal Currents in the Tropical Pacific Ocean: Paths and Vertical Structure ${ }^{\mathscr{O}}$
}

\author{
S. Cravatte, Elodie Kestenare, AND FrédÉRIC MARIN \\ LEGOS, Université de Toulouse, IRD, CNES, CNRS, UPS, Toulouse, France \\ PIERRE DUTRIEUX \\ Lamont-Doherty Earth Observatory, Columbia University, Palisades, New York \\ ERIC FIRING \\ Department of Oceanography, University of Hawai'i at Mānoa, Honolulu, Hawaii
}

(Manuscript received 3 March 2017, in final form 7 July 2017)

\begin{abstract}
The mean subthermocline and intermediate zonal circulation in the tropical Pacific is investigated using a compilation of shipboard ADCP measurements and absolute geostrophic velocities constructed from a highresolution 0-2000-m Argo climatology referenced to a 1000-m velocity field derived from Argo float drifts. This reference field is dominated by basinwide alternating zonal jets with a meridional wavelength of about $3^{\circ}$. In regions where the sampling of SADCP data is sufficient, the consistency between the two independent datasets is striking; using the Argo drift reference is crucial to capture the current structures. Two apparently distinct systems of alternating westward and eastward zonal jets are seen in both datasets equatorward of $10^{\circ}$ : a series of low-latitude subthermocline currents (LLSCs) below the thermocline, extending from about 200 to $800 \mathrm{~m}$, including the eastward Tsuchiya jets; and a series of low-latitude intermediate currents (LLICs), extending from about 700 to at least $2000 \mathrm{~m}$. These systems seem to merge poleward of $10^{\circ}$. Both series shoal to lighter densities eastward. The subthermocline currents and their associated potential vorticity structures undergo a major shift near $155^{\circ} \mathrm{W}$, suggesting some difference in the dynamic regime between the regions west and east of this longitude. Differing behaviors (the LLSCs tend to angle poleward to the east, whereas the LLICs angle slightly equatorward) suggest that these jets may be dynamically distinct, with different forcing mechanisms.
\end{abstract}

\section{Introduction}

In the tropical Pacific, observations from surface drifters, current-meters and acoustic Doppler current profilers (ADCP) installed on TAO/TRITON buoys, and shipboard ADCP (SADCP) data from oceanographic cruises have yielded a good picture of the mean circulation and its variability in the upper $400 \mathrm{~m}$ (e.g., Johnson et al. 2002a; Gouriou and Toole 1993; Rowe et al. 2000). In the equatorial band, the dominant currents in or above the thermocline are the eastward Equatorial

Supplemental information related to this paper is available at the Journals Online website: http://dx.doi.org/10.1175/JPO-D17-0043.s1.

Corresponding author: Sophie Cravatte, sophie.cravatte@ird.fr
Undercurrent (EUC) centered on the equator with a width of about $400 \mathrm{~km}$ and a core reaching $1 \mathrm{~m} \mathrm{~s}^{-1}$, the westward South Equatorial Current (SEC), with its northern and southern branches surrounding the upper part of the EUC, and the eastward North Equatorial Countercurrent (NECC), located between $4^{\circ}$ and $8^{\circ} \mathrm{N}$. Below the EUC the westward Equatorial Intermediate Current (EIC) strengthens and deepens from the central to the western Pacific. It is bounded on both sides of the equator by the eastward Subsurface Countercurrents (SCC) or Tsuchiya jets (Tsuchiya 1975; Gouriou and Toole 1993; Johnson and Moore 1997; Rowe et al. 2000), which appear as deeper poleward extensions of the EUC in the western Pacific but as fully separated features in the central and eastern Pacific. These zonal currents typically have a core velocity of about $15-40 \mathrm{~cm} \mathrm{~s}^{-1}$, and transport 4 to $10 \mathrm{~Sv}\left(1 \mathrm{~Sv} \equiv 10^{6} \mathrm{~m}^{3} \mathrm{~s}^{-1}\right)$ eastward. There 
is a weaker secondary southern SCC around $6^{\circ} \mathrm{S}$ (Wyrtki and Kilonsky 1984; Rowe et al. 2000; Gouriou et al. 2006). All these currents have been described in great detail in Johnson et al. (2002a) and Rowe et al. (2000), but the 400-m depth range of most SADCP data prior to 2000 prevented a full description of their vertical extent.

At greater depths, the oceanic current observations in the intermediate and deeper levels are much more limited. Current profiles from lowered ADCP (LADCP) or acoustically tracked dropsondes are sparse, and calculation of geostrophic currents requires high spatial resolution hydrographic data, sufficient samples to average out internal gravity waves, and a reliable velocity measurement at some reference level. Yet, the few existing synoptic deep velocity profile sections have revealed two interesting patterns. On the equator, westward and eastward deep jets-the so-called equatorial deep jets (EDJ) - alternate vertically with a wavelength of several hundred meters (Eriksen 1981; Firing 1987; Ponte and Luyten 1989; Johnson et al. 2002b; Youngs and Johnson 2015). In addition, Firing (1987) first showed evidence in the central equatorial Pacific of a series of westward and eastward zonal jets at intermediate depths (in the 500-1500-m depth range) alternating meridionally from $3^{\circ} \mathrm{S}$ to $3^{\circ} \mathrm{N}$; the North and South Intermediate Countercurrents (NICC and SICC) flow eastward at $1.5^{\circ}-2^{\circ}$ on both flanks of the westward lower EIC, from 500 to $1500 \mathrm{~m}$. The North and South Equatorial Intermediate Currents (NEIC and SEIC) flow westward at about $3^{\circ}$. These jets of about $10 \mathrm{~cm} \mathrm{~s}^{-1}$ amplitude, sometimes called the "equatorial intermediate current system" (Ascani et al. 2010), were shown to be coherent across the basin at different longitudes when comparing distant synoptic sections (Firing et al. 1998). Their connection with the shallower subthermocline northern and southern SCCs, whose vertical extent is not well known, remains to be described.

More recently, there have been indications that these alternating jet patterns extend poleward of $3^{\circ}$. Gouriou et al. (2006) observed alternating zonal currents in the western Pacific at $165^{\circ} \mathrm{E}$ and $180^{\circ}$ extending from the equator to $10^{\circ} \mathrm{S}$. Similar intermediate jets have also been detected farther from the equator: Qiu et al. (2013a) identified three subthermocline eastward jets [the North Equatorial Undercurrent (NEUC) jets] at $9^{\circ} \mathrm{N}, 13^{\circ}$, and $18^{\circ} \mathrm{N}$ in the western and central part of the basin, using Argo data to compute geostrophic currents relative to 2000-m depth. In the Southern Hemisphere, from $4^{\circ}$ to $30^{\circ} \mathrm{S}$, Taguchi et al. (2012) revealed the presence of alternating jets by applying a meridional high-pass filter to Argo geostrophic velocities, also relative to $2000 \mathrm{~m}$. The filtered structure they obtained was vertically coherent, extending from well below the thermocline to the surface. Thus, no distinction was made between the intermediate jets and the SCCs.

In addition to dynamic height profiles, the Argo program provided a measure of currents at the floats' parking depth. Averaging the parking depth drift velocities from thousands of floats has yielded regional and global maps of 1000-m mean velocity (Davis 2005; Ollitrault et al. 2006; Ascani et al. 2010; Cravatte et al. 2012; Ollitrault and Colin de Verdière 2014; Rosell-Fieschi et al. 2015). Cravatte et al. (2012) confirmed that the zonal jets in the Pacific $3^{\circ} \mathrm{S}-3^{\circ} \mathrm{N}$ band are remarkably coherent across the basin, as suggested by Firing et al. (1998). In addition, they showed that the equatorial intermediate current system is not confined to the near-equatorial band; it is embedded into a broader system of zonal jets, with westward and eastward jets alternating every $1.5^{\circ}$ from $10^{\circ} \mathrm{S}$ to $10^{\circ} \mathrm{N}$ at $1000 \mathrm{~m}$. These jets of about 5 to $10 \mathrm{~cm} \mathrm{~s}^{-1}$, stronger in the Southern Hemisphere, weaken and disappear toward the east. They are also seen in velocities from floats parked at $1500 \mathrm{~m}$, suggesting a deeper extension (Cravatte et al. 2012) and casting doubt on the assumption that currents at $2000 \mathrm{~m}$ are negligible.

Recent observations allow us to revisit the Firing et al. (1998) and Johnson et al. (2002a) papers and to describe the horizontal and vertical structure of the zonal jets in greater detail and over a larger spatial domain than previously. We partially address the following questions:

- What is the vertical extent and coherence of the intermediate jets across the basin?

- Does their vertical extent vary spatially?

- What are the connections between these intermediate structures and the shallower currents below the thermocline, such as the Tsuchiya jets?

First, the number of 2000-m Argo profiles in the tropical Pacific now is sufficient to resolve the meridional structure of the mean zonal geostrophic currents. Referencing these geostrophic currents to a 1000-m velocity field from Argo float drifts provides a 3D absolute geostrophic current field (Willis and Fu 2008; van Sebille et al. 2011; Kessler and Cravatte 2013; Cravatte et al. 2015). Second, the new generation of SADCP instruments measures currents down to 800- or 1200-m depth. In the present study, SADCP velocity measurements collected from research vessels during cruises and transits in the tropical Pacific since 1999 are combined with Argo hydrographic profiles and Argo drift velocities to refine the description of the intermediate zonal currents across the tropical Pacific. The data used and the methods to combine them are described in section 2 . In section 3, vertical sections of zonal currents are 
shown, averaged in longitude bands, and the inferred current patterns and connections throughout the tropical Pacific are described in section 4. The implications for theories and models are discussed in section 5 .

\section{Data and methods}

\section{a. SADCP data}

We gathered SADCP data from the low-latitude tropical Pacific, during 1999-2015 (Table S1 in the supplemental information; Fig. 1; 190 cruises). Most of the data (128 cruises) were provided by the Joint Archive for Shipboard ADCP (JASADCP) at the University of Hawaii, with a large fraction from the NOAA ship Ka'imimoana, servicing the TAO array of moored buoys. From 2004 to its retirement in 2012, its $75-\mathrm{kHz}$ Ocean Surveyor (OS75) instrument provided current measurements to $600-750 \mathrm{~m}$. Meridional sections at $165^{\circ} \mathrm{E}, 180^{\circ} \mathrm{E}, 170^{\circ} \mathrm{W}, 155^{\circ} \mathrm{W}, 140^{\circ} \mathrm{W}, 125^{\circ} \mathrm{W}, 110^{\circ} \mathrm{W}$, and $95^{\circ} \mathrm{W}$ were regularly sampled. Data from the Kilo Moana, equipped with a $38 \mathrm{-kHz}$ Ocean Surveyor instrument (OS38), provide direct current measurements down to about $1200 \mathrm{~m}$. Four voyages onboard the R/V Atalante were collected from Ifremer, the French data center; 30 cruises came from the ships servicing the TRITON array, the R/V Mirai and R/V Kaiyo from the Japan Agency for Marine-Earth Science and Technology (JAMSTEC); and 26 came from the Japan Meteorological Agency (JMA), from the Ryofu Maru and Keifu Maru vessels, repeating the $137^{\circ} \mathrm{E}$ section. Data from two additional cruises, the Iron EUC cruise onboard the R/V Kilo Moana (Slemons et al. 2010) and the M90 cruise onboard the German R/V Meteor (Czeschel et al. 2015) were kindly made available by the principal investigators (PIs).

All data retrieved from the JASADCP center were from their "standard subset" containing hourly averages interpolated to a $10-\mathrm{m}$ vertical grid. For the other datasets, SADCP data were provided as 5- to 15-min temporal averages with 5- to 24-m vertical resolution. They were then averaged and interpolated to the 1-h, $10-\mathrm{m}$ vertical grid. The complete dataset was mapped on a $0.25^{\circ}$ latitude by $1^{\circ}$ longitude grid using a simple Gaussian weighting function with $0.25^{\circ}$ latitude and $3^{\circ}$ longitude decorrelation scales, independent of the timing of the measurements, with windows of $0.5^{\circ}$ of latitude and $6^{\circ}$ of longitude.

\section{b. Argo float drifts}

Argo profiling floats (Argo 2000) provide vertical profiles of temperature and salinity every 10 days. They dive to the bottom of their profile (usually $2000 \mathrm{~m}$ ) and rise to the surface where they spend typically a few hours before descending to their parking depth. Between dives, they drift for about 9 days at their parking depth; the positions and times of transmissions before and after each dive can be used to estimate the mean subsurface Lagrangian velocities during the drift period (e.g., Park et al. 2005; Ollitrault and Rannou 2013; Kessler and Cravatte 2013).

Ollitrault and Rannou (2013) recently produced the ANDRO dataset, with validated parking pressures and quality-controlled subsurface displacements for the global ocean from all Argo floats until 31 December 2009. We used this dataset for the pre-2010 period. For the later period, we updated and extended the work done by Cravatte et al. (2012), gathering all Argo floats that entered the $20^{\circ} \mathrm{S}-20^{\circ} \mathrm{N}$ region between $120^{\circ} \mathrm{E}$ and $70^{\circ} \mathrm{W}$, from January 2010 to December 2013, and computed their parking depth drift velocities. Each float trajectory and the parameters of its dive were visually inspected to eliminate obvious errors (e.g., a float not drifting at its parking depth). Especially, the pressure at the parking depth was computed and inspected carefully, resulting in a rejection of about $7 \%$ of the subsurface drifts. In the tropical Pacific Ocean, most Argo floats have a parking depth around $1000 \mathrm{~m}$. The subsurface velocities at $1000 \mathrm{~m}$ were thus mapped to produce a mean monthly climatological field on a $1^{\circ}$ longitude by $0.25^{\circ}$ latitude grid, using an optimal objective interpolation. Details of the methods and error analysis are described in Cravatte et al. (2012).

\section{c. Argo floats hydrographic data}

Gridded products of temperature and salinity based on Argo data are provided by various institutions, at different resolutions and with different interpolation scales. For this study we selected the highest-resolution product: the mean Argo temperature and salinity gridded climatology with a $1 / 6^{\circ}$ resolution (Roemmich and Gilson 2009; updated to include 2004-14, downloaded from http://sio-argo.ucsd.edu/RG_Climatology.html). Its vertical resolution is $10 \mathrm{~m}$ down to $180 \mathrm{~m}, 20 \mathrm{~m}$ between 180 and $500 \mathrm{~m}, 50 \mathrm{~m}$ between $500 \mathrm{~m}$ and $1400 \mathrm{~m}$, and $100 \mathrm{~m}$ below.

Dynamic height anomalies and derived zonal geostrophic shear both on and off the equator were computed following the method presented by Picaut and Tournier (1991) using a 1000-m reference level. The 1000-m Argo float drift then provided the constant of integration for vertically integrating the geostrophic shear to obtain a field of mean absolute geostrophic velocity, hereafter called the Argo velocity product.

The potential vorticity is computed as $\mathrm{PV}=$ $\left\{[f-(\partial u / \partial y)] / \rho_{0}\right\}(\partial \rho / \partial z)$, where $f$ is the Coriolis 


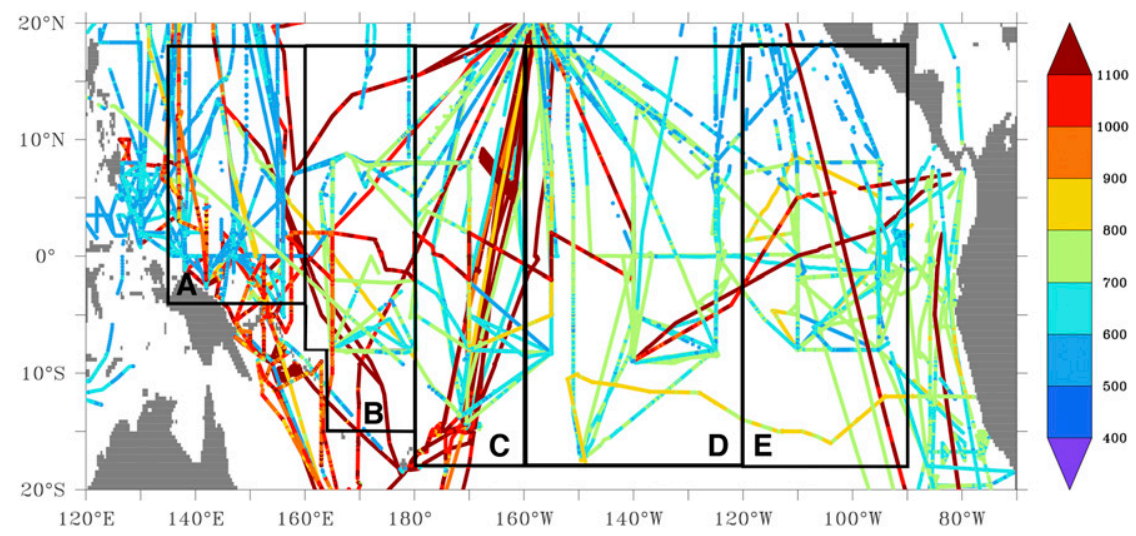

FIG. 1. Sampling of SADCP data: tracks of the cruises included in the database. The colors represent the depth of the deepest measurement. Boxes with letters indicate the different areas considered and are referenced in various figures.

parameter, $\partial u / \partial y$ is the meridional gradient of the absolute geostrophic velocity, $\partial \rho / \partial z$ is the vertical density gradient based on the difference between potential densities referenced to their midpoint, and $\rho_{0}$ is a constant reference density $\left(10^{3} \mathrm{~kg} \mathrm{~m}^{-3}\right)$.

\section{Vertical structure of the jets}

\section{a. Comparison of SADCP velocities and Argo drifts at $1000 \mathrm{~m}$}

Before describing the vertical structure of the zonal currents, we check for consistency between the SADCP measurements and the Argo drifts at $1000 \mathrm{~m}$. Figure 2 shows all hourly SADCP velocity measurements (pink) and their time and zonal mean (red) at 1000-m depth in the best-sampled region, between $179^{\circ} \mathrm{E}$ and $160^{\circ} \mathrm{W}$, and in a less sampled region $\left(160^{\circ} \mathrm{E}-180^{\circ}\right)$. Overlaid are all 10-day average Argo velocity estimates at $1000 \mathrm{~m}$ in the same regions (gray) and their time and zonal mean (black) as well as the envelope of the first annual harmonic, which dominates the seasonal variability (Cravatte et al. 2012; Marin et al. 2010). Both datasets cover very similar periods (2003-13 for the Argo floats, 2004-15 for the SADCP data) and are both fairly well distributed among the seasons.

As in Cravatte et al. (2012), a series of alternating westward and eastward zonal jets with a meridional wavelength of $3^{\circ}$ and an amplitude of $5-10 \mathrm{~cm} \mathrm{~s}^{-1}$ is seen in both longitude ranges, and the mean meridional current seen by the Argo floats is close to zero, as it is in the whole basin, except near the coasts (not shown). The coherence between the two datasets is striking in the $179^{\circ} \mathrm{E}-160^{\circ} \mathrm{W}$ region; the mean 1000 -m zonal jets inferred from SADCP data or Argo drift data are located at the same latitudes and have the same amplitude. They also exhibit similar variability around the mean, with a maximum at the equator reaching $\pm 35 \mathrm{~cm} \mathrm{~s}^{-1}$, much higher than the mean seasonal variability shown in Cravatte et al. (2012) and Marin et al. (2010). Similar consistency is observed for the meridional velocity estimates, which are dominated by the variability at intraseasonal time scales; the mean is near zero. There is a somewhat higher variability for the hourly SADCP currents than for the Argo drifts. The two datasets use completely different instruments and methods and have different spatial and temporal sampling. Their consistency, despite these differences, gives us confidence in the structures seen and in using both SADCP and Argo absolute geostrophic velocities for describing the vertical structure of the zonal jets.

However, Fig. 2 also demonstrates the high variability in synoptic measurements, so large sample sizes are needed to obtain reliable velocity means. Between $160^{\circ} \mathrm{E}$ and $180^{\circ}$, where the SADCP sections are far less numerous than between $179^{\circ} \mathrm{E}$ and $160^{\circ} \mathrm{W}$, the mean velocities differ greatly from mean Argo drifts at latitudes where only one cruise sampled the $1000-\mathrm{m}$ currents (e.g., between $2.5^{\circ}$ and $\left.8^{\circ} \mathrm{N}\right)$. Therefore, we must keep in mind that the mean circulation obtained by averaging over an insufficient number of data may be dominated by synoptic variability.

\section{b. Vertical sections of velocity in the central Pacific}

The best SADCP sampling is in the $179^{\circ} \mathrm{E}-160^{\circ} \mathrm{W}$ longitude band, where many Kilo Moana transits provided measurements down to $1200 \mathrm{~m}$. The mean zonal current section shows the complexity of the circulation (Fig. 3). In the upper ocean, the broad-scale westward South Equatorial Current (from $18^{\circ} \mathrm{S}$ to $4^{\circ} \mathrm{N}$ ) and North Equatorial Current (from $9^{\circ}$ to $18^{\circ} \mathrm{N}$ ) are separated 
Zonal velocity Meridional velocity Zonal velocity Meridional velocity Number

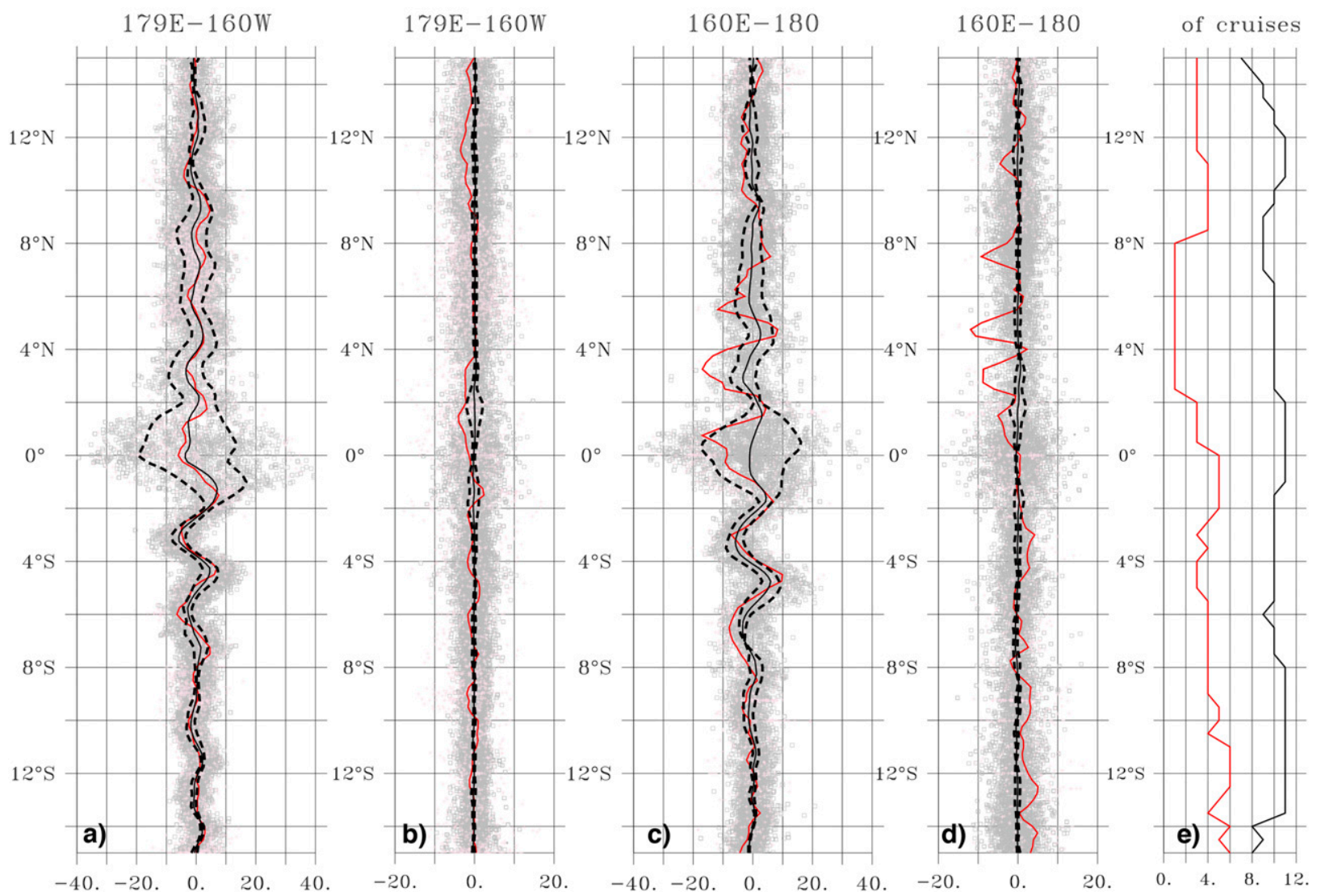

FIG. 2. Comparison of the velocities at 1000-m depth from SADCP data and the Argo drift velocities in two longitudinal boxes. In light gray, all Argo drifts Lagrangian velocity estimates, as a function of latitude. In black, their time and zonal mean and their first annual harmonic envelope (dashed black). In pink, all SADCP measurements in the same box; in red, the SADCP time and zonal mean. (a) Zonal velocity in the $179^{\circ} \mathrm{E}-160^{\circ} \mathrm{W}$ box. (b) As in (a), but for the meridional velocities in the same box. (c),(d) As in (a) and (b), but for the $160^{\circ} \mathrm{E}-180^{\circ}$ box. (e) Number of independent cruises with SADCP observations in the $179^{\circ} \mathrm{E}-160^{\circ} \mathrm{W}$ box (black) and $160^{\circ} \mathrm{E}-180^{\circ}$ box (red), in boxes of $0.5^{\circ}$ latitude.

by the eastward North Equatorial Countercurrent (centered at $5^{\circ} \mathrm{N}$ ). In the thermocline, the EUC is centered on the equator at $150 \mathrm{~m}$, with the eastward SCCs (labeled A in Fig. 3) appearing about $3^{\circ}$ on either side of the equator as two downward lobes bounding the westward EIC. The secondary southern SCC (labeled B), studied by Rowe et al. (2000), is very clearly observed at $5.5^{\circ} \mathrm{S}$, from 300 to $750 \mathrm{~m}$. Additional subthermocline eastward zonal currents are also discernable above $800 \mathrm{~m}$ beneath the westward winddriven South Equatorial Current; the third, fourth, and fifth eastward jets are centered at $9^{\circ}, 11.5^{\circ}$, and $14^{\circ} \mathrm{S}$, with successively deeper cores. The fourth and fifth eastward jets extend below $1000 \mathrm{~m}$. At these longitudes, there is no strong Northern Hemisphere equivalent of this series of eastward zonal jets; some structures are discernable, like the ones centered at $7^{\circ}$, $12^{\circ}$, and $15^{\circ} \mathrm{N}$, but they are not as clearly defined as their southern counterparts. This is somewhat at odds with the study by Qiu et al. (2013a), showing subthermocline eastward jets throughout the North Pacific. However, this longitude band corresponds to the region where their jets are less distinct; zonal jets in other regions (in particular in the western part of the basin) are quite consistent with Qiu et al. (2013a) findings. Cores of westward velocities are also observed at $10^{\circ} \mathrm{S}, 7^{\circ} \mathrm{S}, 3^{\circ} \mathrm{S}, 6^{\circ} \mathrm{N}, 9^{\circ} \mathrm{N}$, and $14^{\circ} \mathrm{N}$, between these eastward jets, connected with the westward overlying SEC and NEC. We suggest calling this system of alternating westward and eastward jets, north and south of the equator, the low-latitude subthermocline currents (LLSCs).

The other striking feature is the deeper system of alternating intermediate zonal jets, which are also seen at $1000 \mathrm{~m}$ with Argo float drifts (Cravatte et al. 2012; Ascani et al. 2010; Ollitrault and Colin de Verdiere 2014). 

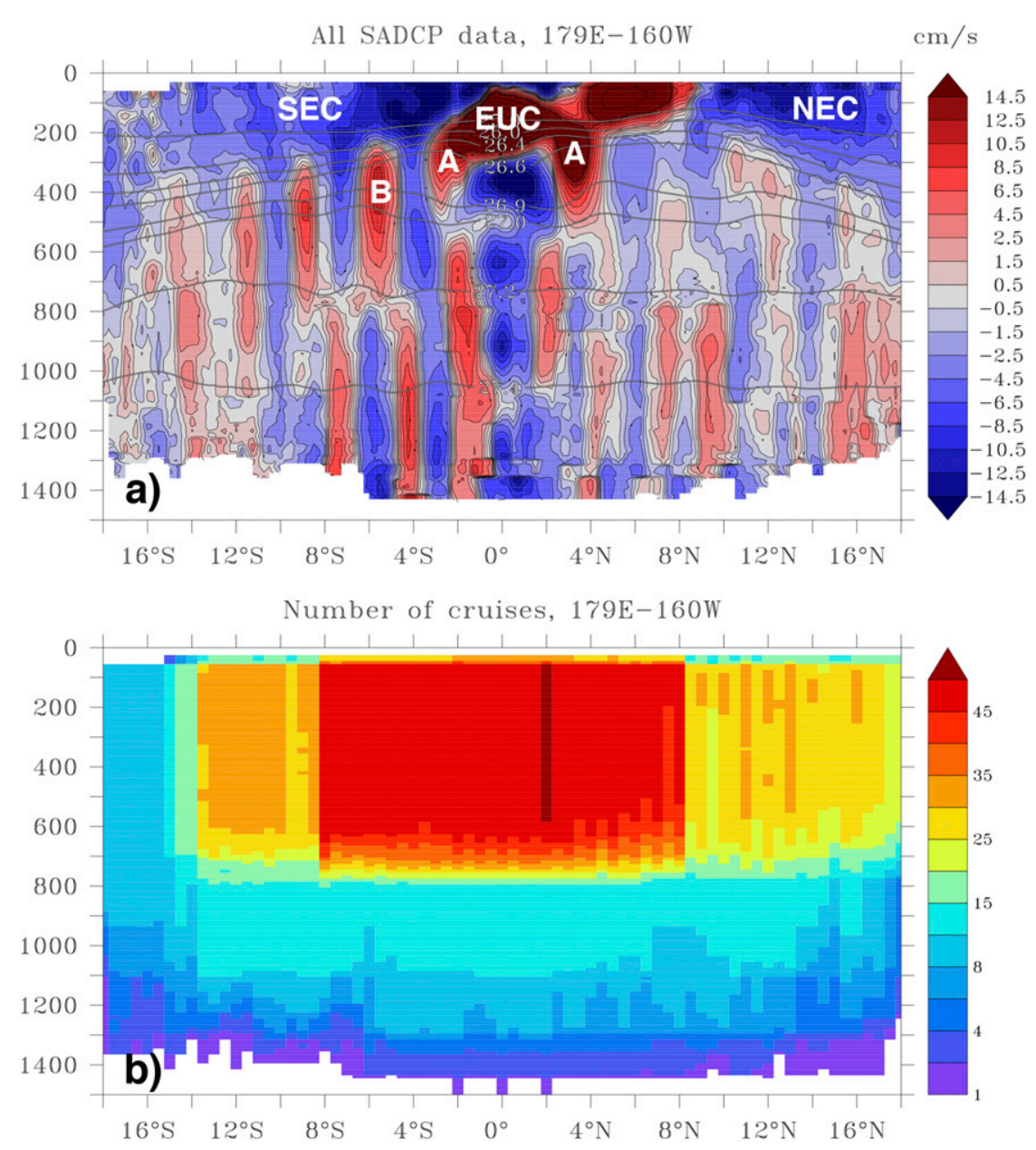

FIG. 3. (a) Zonal currents in the $179^{\circ} \mathrm{E}-160^{\circ} \mathrm{W}$ box (Box C in Fig. 1), as a function of depth and latitude, from the SADCP gridded product. Superimposed in black are the isopycnals from 25 to $27.4 \mathrm{~kg} \mathrm{~m}^{-3}$. Abbreviations are EUC for Equatorial Undercurrent, SEC for South Equatorial Current, and NEC for North Equatorial Current. A and B letters indicate the first and secondary Tsuchiya jets, respectively. Results are shown if data from at least two cruises are available. (b) Number of independent cruises with SADCP observations in $0.5^{\circ}$ latitude boxes, corresponding to the Gaussian weight scale used in the gridding.

We suggest calling these westward and eastward jets the low-latitude intermediate currents (LLICs). They appear to be below and distinct from the LLSCs, at least within $10^{\circ}$ of the equator, and stronger in the Southern Hemisphere, with a meridional spacing of about $1.5^{\circ}$ between alternating jets. At the equator, the Lower Equatorial Intermediate Current (L-EIC) is westward. Eastward jets are located at $1.75^{\circ} \mathrm{S}$ and $2^{\circ} \mathrm{N}$ (the Southern and Northern Intermediate Countercurrents), at $4.25^{\circ} \mathrm{S}$, $4.5^{\circ} \mathrm{N}, 7.5^{\circ} \mathrm{S}, 7.5^{\circ} \mathrm{N}$, and $9.25^{\circ} \mathrm{N}$, with maximum velocities of about 4 to $8 \mathrm{~cm} \mathrm{~s}^{-1}$. Additional zonal eastward jets have a signature at $1000 \mathrm{~m}$ poleward of $10^{\circ}$, but it is not clear if they are part of the intermediate alternating jets system or of the LLSCs system. In most places the eastward jets are separated by equally prominent westward flows.

Figure $3 \mathrm{~b}$ shows that many more cruises contribute to the mean above $700 \mathrm{~m}$ than below, raising the question of whether this is causing an artificial break between the LLSCs and the deeper LLICs. However, the mean of the SADCP data with profiles deeper than $1000 \mathrm{~m}$, Fig. $4 \mathrm{a}$, is very similar to Fig. $3 \mathrm{a}$ in the Southern Hemisphere, demonstrating that the nonuniform vertical sampling in the latter is not causing major artifacts. In the Northern Hemisphere, the LLSCs appear surprisingly stronger and more clearly defined in Fig. 4a when fewer cruises are used to compute the mean. This raises the question of whether the positions and core magnitude of the subthermocline 

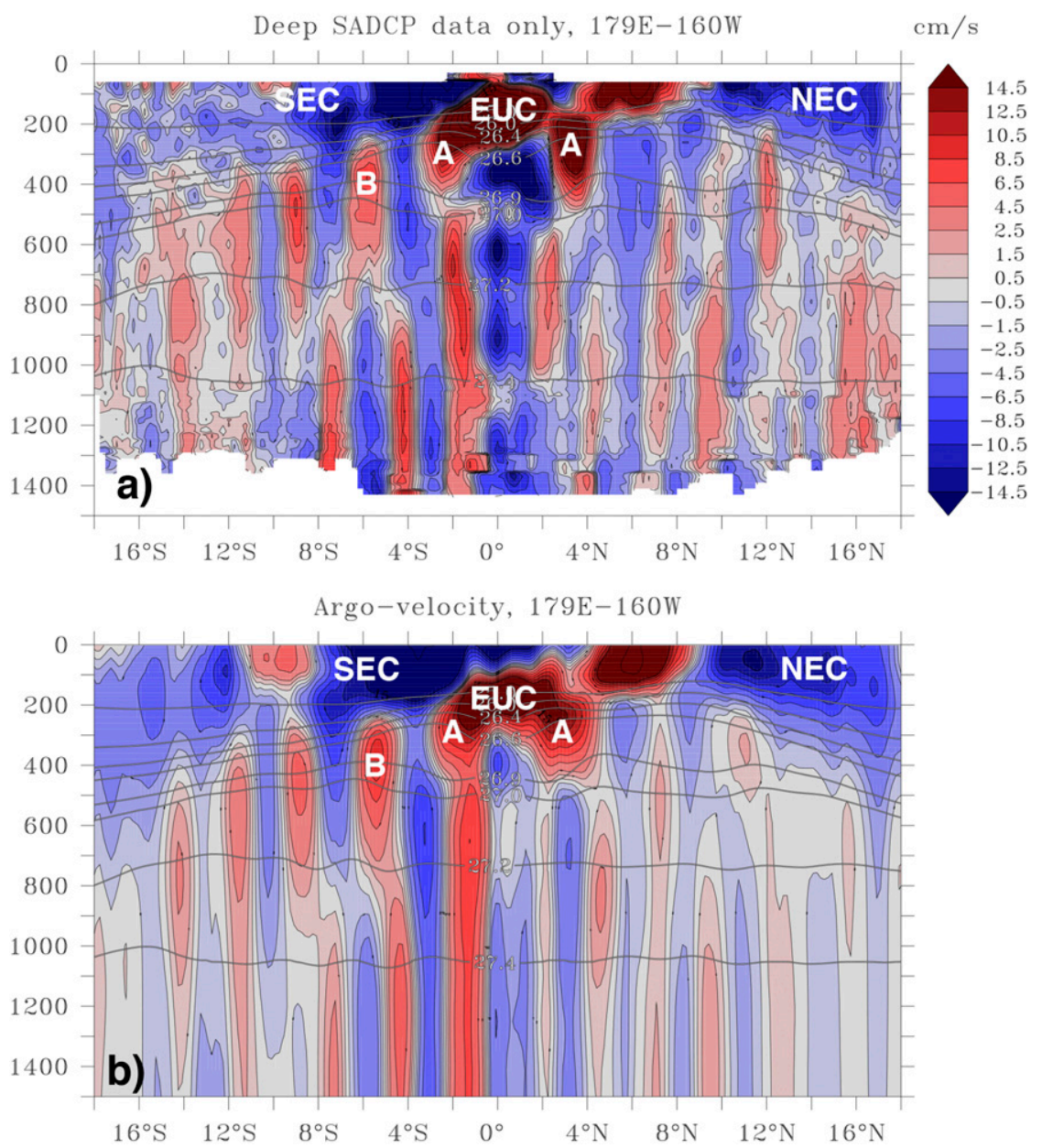

FIG. 4. (a) Mean zonal currents in the $179^{\circ} \mathrm{E}-160^{\circ} \mathrm{W}$ box (Box C in Fig. 1) as a function of depth and latitude but only from SADCP data extending to at least 1000-m depth. (b) Mean absolute geostrophic zonal currents (see text) averaged in the same longitudinal box. Superimposed on both panels in black are the isopycnals from 25 to $27.4 \mathrm{~kg} \mathrm{~m}^{-3}$. Abbreviations are the same as in Fig. 3.

jets are more variable in the Northern Hemisphere so that they tend to partly average out in the mean.

The absolute geostrophic currents computed from the gridded Argo profiles and referenced to the 1000m Argo drift velocity (Fig. 4b) are remarkably similar to the SADCP means (Figs. 3a, 4a), particularly in the Southern Hemisphere. Most of the subthermocline currents in one have clear counterparts in the other, in nearly the same location, despite the vast differences in sampling. We conclude that given sufficient sampling to represent the mean over a few years, both methods are reliable, and the features are robust. The referenced geostrophic estimate has the advantage of better basinwide sampling and greater depth range. Inclusion of the 1000-m reference velocity is critical for getting an accurate picture of currents below the thermocline. Comparing the geostrophic currents over the full 2000-m depth range from the referenced product to the currents relative to $2000 \mathrm{~m}$, we see much better agreement between the former and the SADCP observations over the full latitude range (Fig. 5). The reference at $1000 \mathrm{~m}$ is thus indispensable to depict the intermediate equatorial currents, which appear to extend to at least $2000 \mathrm{~m}$ and also to represent correctly the relatively shallow LLSCs. Qiu et al. (2013a) stated that their jets below the North Equatorial Current were largely insensitive to the addition of a 2000-m reference velocity. We find that these jets do exist in both the referenced and nonreferenced products but differ significantly in core velocity magnitude and structure.

To show the relation between the density structure and the currents, potential density relative to the surface is computed from the gridded Argo product (Figs. 3, 4, 5). 

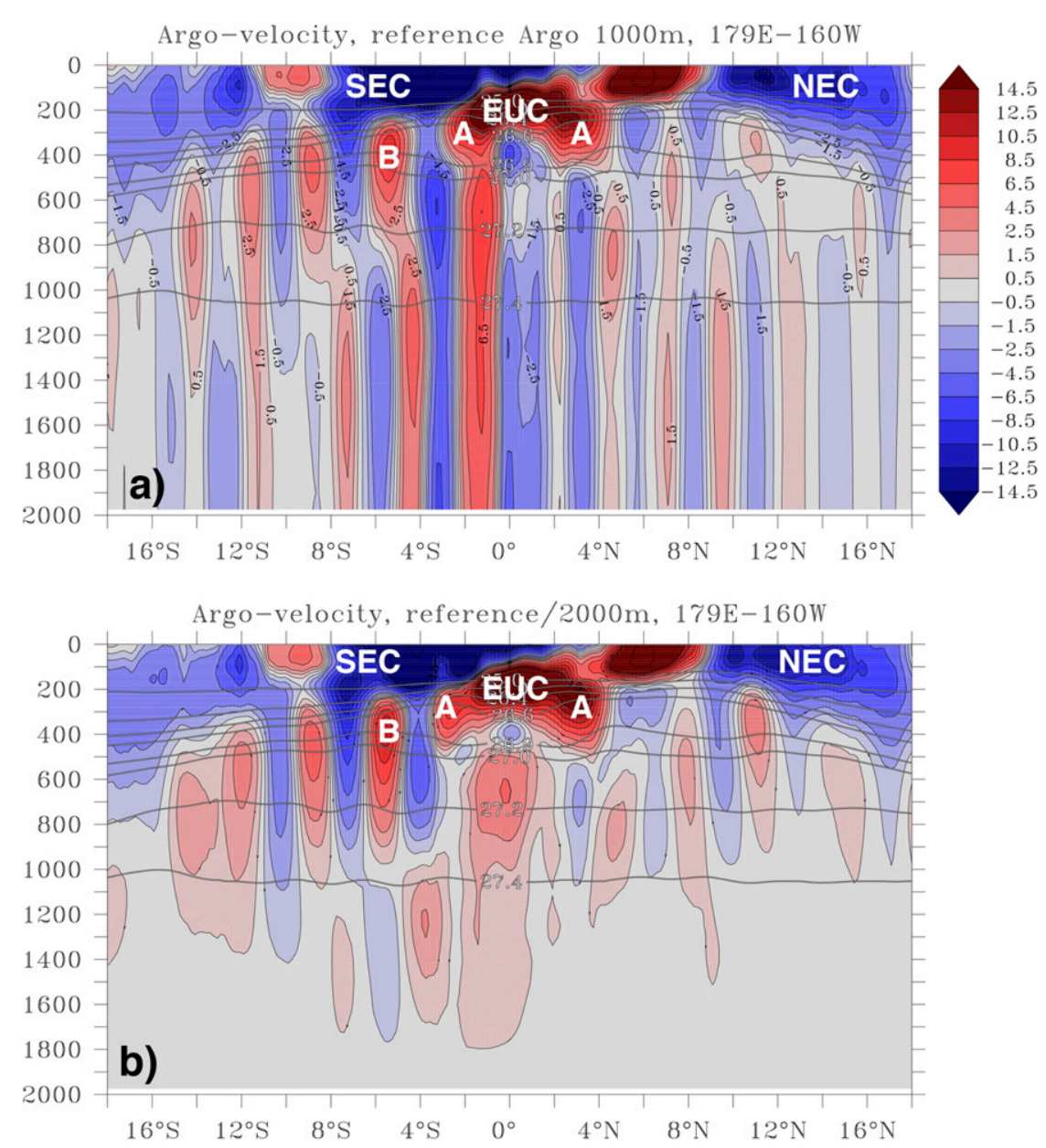

FIG. 5. (a) As in Fig. 4b, but shown on a deeper vertical extent, from 0 to 2000-m depth. (b) Mean geostrophic zonal currents averaged in the same longitudinal box, referenced to a level of no motion at $2000 \mathrm{~m}$. Superimposed on both panels in black are the isopycnals from 25 to $27.4 \mathrm{~kg} \mathrm{~m}^{-3}$.

The $25.0 \mathrm{~kg} \mathrm{~m}^{-3}$ isopycnal is in the core of the thermocline. The top of the $13^{\circ} \mathrm{C}$ thermostad (Tsuchiya 1981) is approximately the $26.4 \mathrm{~kg} \mathrm{~m}^{-3}$ isopycnal at the base of the permanent thermocline, and the $26.9 \mathrm{~kg} \mathrm{~m}^{-3}$ isopycnal represents the bottom of the thermostad. The primary SCCs form the poleward edges of the thermostad; higher-latitude LLSCs get deeper and denser poleward from the equator, a behavior similar to the Qiu et al. (2013a) jets north of $10^{\circ} \mathrm{N}$. The LLICs are centered in the intermediate water range, transporting waters denser than $27-27.2 \mathrm{~kg} \mathrm{~m}^{-3}$.

\section{c. Velocity sections in other longitudinal bands}

In the northwestern part of the basin, numerous regular cruises (Dutrieux 2009; Nakano et al. 2005; Qiu et al. 2017) show the pattern of zonal jets (Fig. 1; Fig. S1). Zonal currents averaged in the $135^{\circ}-160^{\circ} \mathrm{E}$ box $\mathrm{A}$, north of $4^{\circ} \mathrm{S}$ (to avoid picking values inside the Solomon Sea; Fig. 6), show the EUC, centered at $1^{\circ} \mathrm{N}$, and the northern SCC at $3^{\circ} \mathrm{N}$, not entirely separated from the EUC and the NECC. Below, clearly distinct from the northern SCC, the eastward North Intermediate Countercurrent extends from about $650 \mathrm{~m}$ to deeper than $1200 \mathrm{~m}$, centered at approximately $2^{\circ} \mathrm{N}$ and reaching a maximum of $10 \mathrm{~cm} \mathrm{~s}^{-1}$ at $820 \mathrm{~m}$. The South Intermediate Countercurrent, at $2^{\circ} \mathrm{S}$, is not as strong as its northern counterpart, probably because of the proximity of the coast; surprisingly, it appears to begin at 700-1200-m depths in the far west of the basin, from the Papua New Guinea coast in the northern Bismarck Sea (not shown). Previously it had been shown to fully develop only east of New Ireland (Cravatte et al. 2012), perhaps fed by the New Ireland Coastal Intermediate Current (Dutrieux 2009). Identical structures are shown in the Argo velocity absolute geostrophic currents for this latitude band (Fig. 6b). North of $4^{\circ} \mathrm{N}$, zonal currents in the SADCP and Argo velocity products are similar but with 

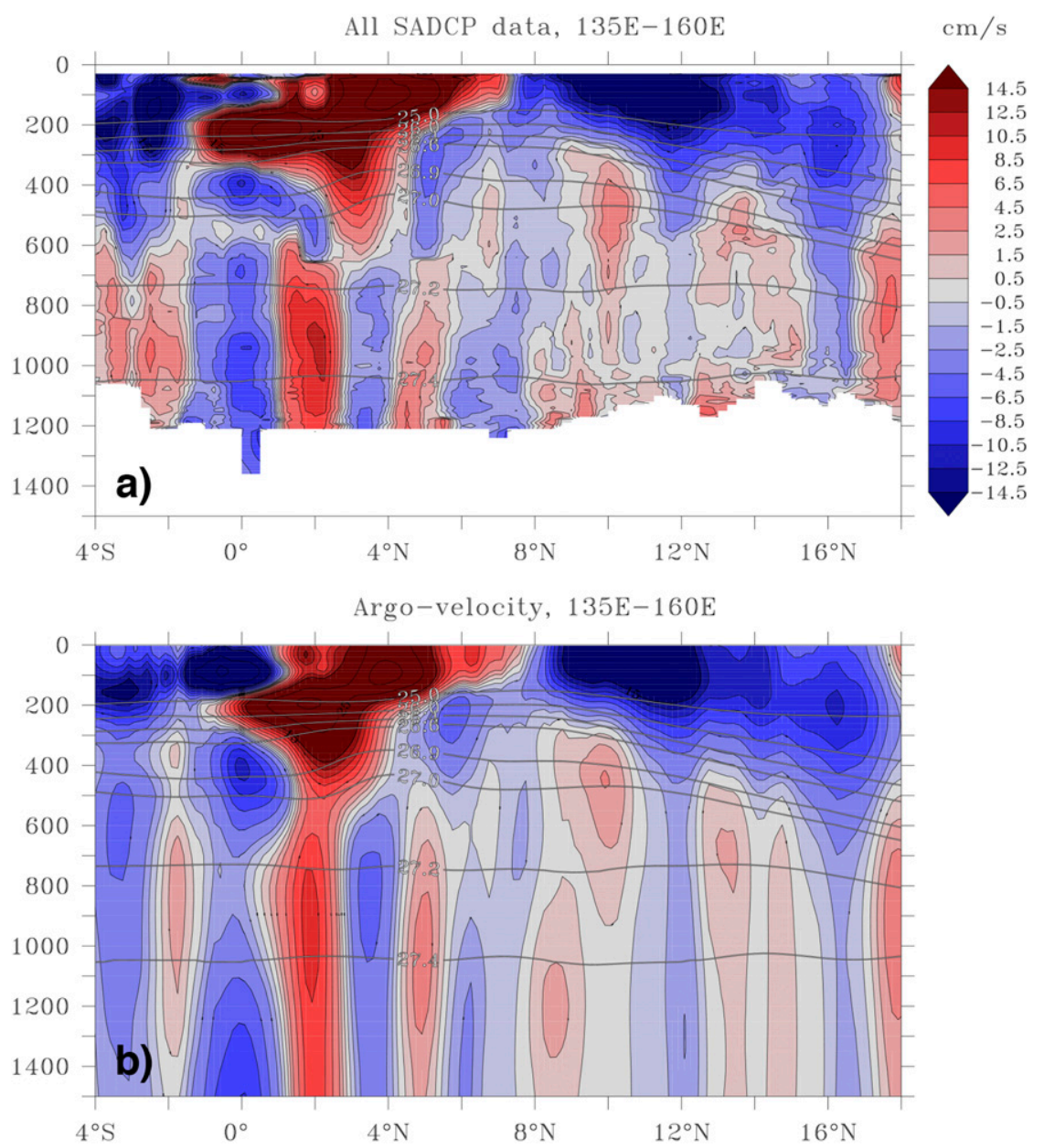

FIG. 6. (a) Mean zonal currents for $135^{\circ}-160^{\circ} \mathrm{E}$ (box A in Fig. 1), as a function of depth and latitude, from $4^{\circ} \mathrm{S}$ to $18^{\circ} \mathrm{N}$, from SADCP data. Results are shown if data from at least two cruises are available. (b) Mean absolute geostrophic zonal currents averaged in the same longitudinal box. Superimposed on both panels in black are the isopycnals from 25 to $27.4 \mathrm{~kg} \cdot \mathrm{m}^{-3}$.

somewhat different amplitudes. Eastward currents just below the thermocline are visible at $10^{\circ}, 13^{\circ}$, and $17.5^{\circ}-18^{\circ} \mathrm{N}$ in both datasets and at $7^{\circ} \mathrm{N}$ in the SADCP dataset, corresponding to a local minimum in westward velocities in the Argo velocity product. These jets in the $26.4-27.3 \mathrm{~kg} \mathrm{~m}^{-3}$ isopycnal layer, with velocities up to $5 \mathrm{~cm} \mathrm{~s}^{-1}$, are the NEUC jets described by Qiu et al. (2013a). They are located at the same latitudes but with a different vertical structure, since Qiu et al. (2013a) did not use a 1000-m absolute velocity reference. Deeper, intermediate eastward jets are observed at $5^{\circ}$ and $8.5^{\circ} \mathrm{N}$, with westward jets at $3.5^{\circ}$ and $6^{\circ} \mathrm{N}$.

Between the far western box A and the well-sampled central box $\mathrm{C}$, box $\mathrm{B}$ spans the open-ocean portions of the $160^{\circ} \mathrm{E}-180^{\circ}$ band, with fewer cruises (Fig. 1; Fig. S1). In both the SADCP and the Argo velocity products, the similarities between currents in this band and in its neighbors are strong; all of the main features previously noted are present (Fig. 7).

East of $160^{\circ} \mathrm{W}$, in box D, the SADCP sampling becomes very sparse below $800 \mathrm{~m}$ and south of $10^{\circ} \mathrm{S}$ (Fig. 1; Fig. S2). The Argo velocity product, however, reveals a beautiful series of LLSCs in the Southern Hemisphere (Fig. 8). The main difference compared to the bands west of $160^{\circ} \mathrm{W}$ is that the first southern and northern SCCs, located at $4^{\circ}-5^{\circ}$, are fully separated from the EUC. In the Argo velocity product, the secondary SCC is at $7^{\circ} \mathrm{S}$, clearly shifted southward of its $5.5^{\circ} \mathrm{S}$ latitude in the $179^{\circ} \mathrm{E}-160^{\circ} \mathrm{W}$ area. This secondary SCC is not apparent in the SADCP product, where the following SCC is observed at $9.5^{\circ}-10^{\circ} \mathrm{S}$. It is possible that the secondary SCC is missing from the SADCP mean because of inadequate space-time sampling within this wide longitude band. Additional multiple LLSCs are seen in the Argo velocity product, deepening and becoming denser 

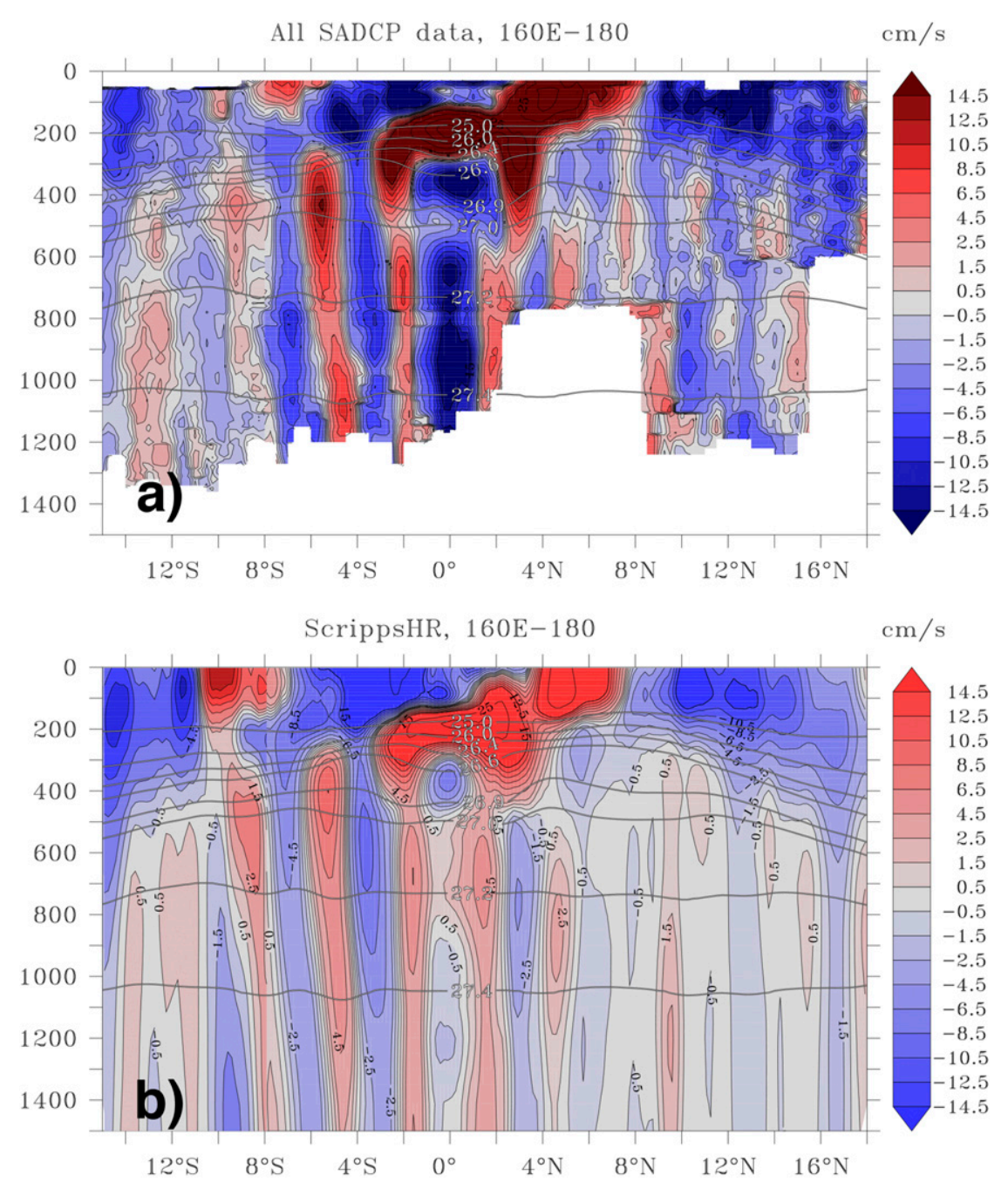

FIG. 7. As in Fig. 4, but for $160^{\circ} \mathrm{E}-180^{\circ}$ (box B in Fig. 1).

southward. These multiple jets are not as clear in the Northern Hemisphere. Below, at intermediate depths, alternating westward and eastward zonal currents (LLICs) are detected in both hemispheres, consistent with Cravatte et al. (2012). In this longitude band, however, they are not as clearly distinct from the LLSCs as farther west.

Finally, in the eastern Pacific, between $120^{\circ} \mathrm{W}$ and the Galapagos Islands, the EUC is much shallower, with a maximum above 100-m depth (Fig. 9). The two SCCs are located in both datasets at $6^{\circ} \mathrm{S}, 200-\mathrm{m}$ depth, and $5^{\circ} \mathrm{N}$, $150-\mathrm{m}$ depth. The secondary SCC is seen at $10^{\circ} \mathrm{S}, 300 \mathrm{~m}$, but the other subsurface jets are much less resolved (Fig. S2). In the Argo velocity product the mean zonal jets are shallower, and the mean zonal currents magnitude is everywhere less than $1 \mathrm{~cm} \mathrm{~s}^{-1}$ below $600 \mathrm{~m}$. East of the Galapagos, synoptic SADCP sections show eastward zonal jets above $700 \mathrm{~m}$ at varying locations from the equator to $20^{\circ} \mathrm{S}$ (Czeschel et al. 2015), but there are not enough measurements for a stable time average. These jets have been suggested to feed the Peru Current System in the far eastern Pacific (Cravatte et al. 2007; Montes et al. 2010) and to ventilate the oxygen minimum zone (Dietze and Loeptien 2013; Czeschel et al. 2011, 2015).

\section{Multiple LLSCs versus LLICs: Two independent objects?}

a. Following the SCCs and the intermediate zonal jets across the basin

The current sections averaged in broad longitude bands show that many of the subthermocline and intermediate currents can be tracked from band to band. To focus on their zonal continuity and paths, we 

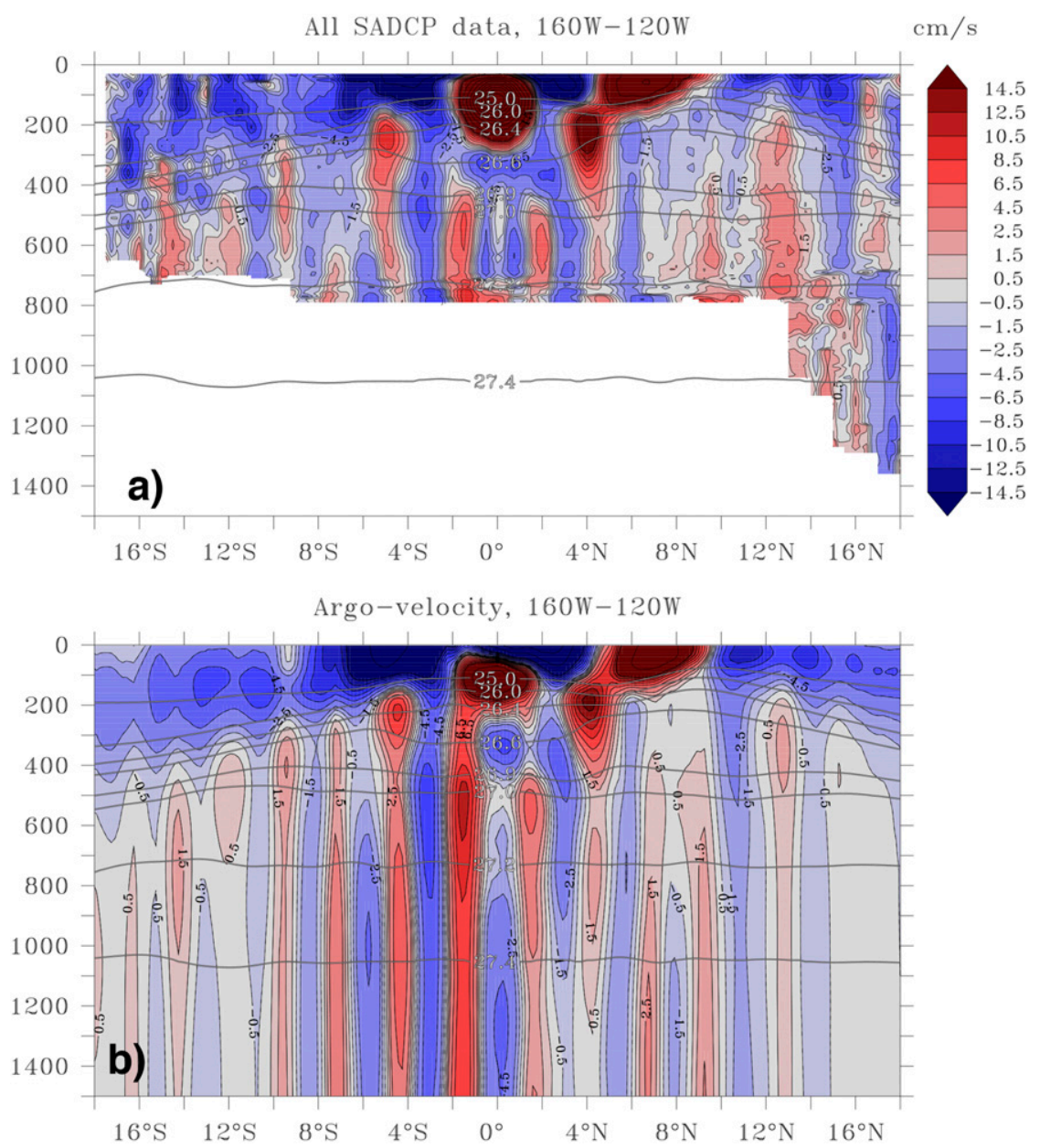

FIG. 8. As in Fig. 4, but for $160^{\circ}-120^{\circ} \mathrm{W}$ (box D in Fig. 1).

calculated the core positions of the eastward jets using two methods. For the intermediate currents, we used an automated procedure to identify local eastward maxima in the Argo velocity product averaged over the $27.2-27.65 \mathrm{~kg} \mathrm{~m}^{-3}$ potential density layer (heavy black lines in Fig. 10). These isopycnals were chosen based on Figs. 3 to 8 , as the upper bound and lowest possible bound above $2000 \mathrm{~m}$ of the LLICs. For the shallower subthermocline currents, we visually identified the core potential densities and latitudes on sections every $5^{\circ}$ in longitude in both SADCP (when resolved; Fig. 10, squares) and absolute geostrophic currents (Fig. 10, circles). This method is subjective; the zonal jets often extend over a large depth range, and it is quite difficult to identify unambiguously the velocity and density core. Moreover, SADCP fields are noisy, and when the number of cruises is small, transient features can be erroneously identified as jets. Yet, despite all difficulties inherent in the methods, the main eastward jets of the LLSCs system can be followed across the basin.
The plot of core locations, with potential densities of the subthermocline cores, gives a basin-scale confirmation of inferences from the longitude band sections as follows:

- The multiple LLSCs get deeper and denser poleward; they get shallower and lighter from west to east.

- The LLICs tracks are often interrupted, and the eastward jets (and westward jets, not shown) appear broken up into several segments, particularly in the Northern Hemisphere. Some of these interruptions may be linked to topographic barriers or to local undersampling.

- There is a clear distinction between the LLICs and the multiple LLSCs equatorward of about $10^{\circ}$. The multiple LLSCs diverge from the equator from west to east, whereas the LLICs stay remarkably constant in latitude, with a tendency to slant slightly equatorward from west to east only in the westernmost part of the basin [as demonstrated in Cravatte et al. (2012) 

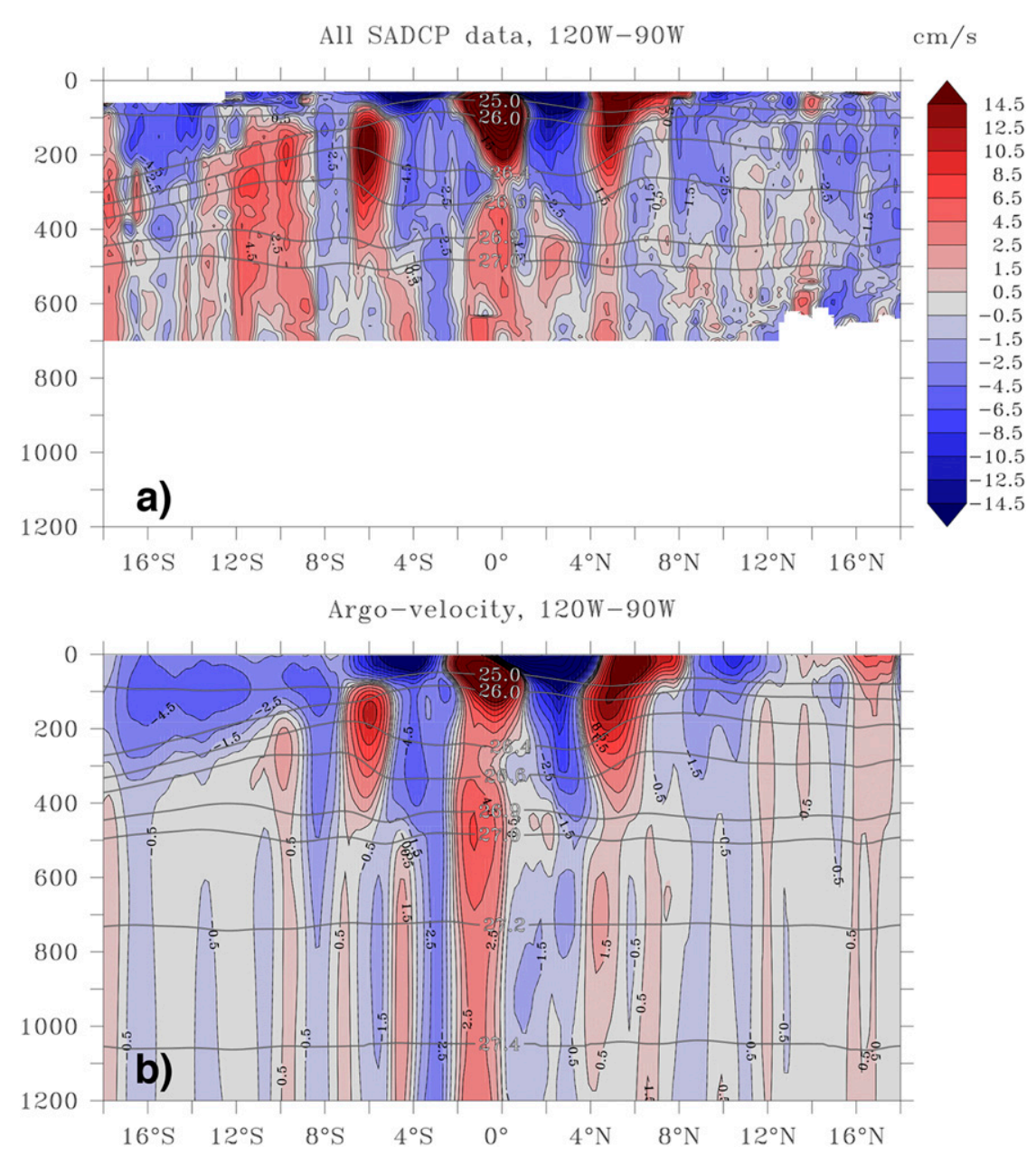

FIG. 9. As in Fig. 4, but for $120^{\circ}-90^{\circ} \mathrm{W}$ (box E in Fig. 1).

at $1000 \mathrm{~m}]$. Thus, the two systems are generally not vertically aligned except in the $160^{\circ} \mathrm{E}-180^{\circ}$ band south of the equator, as previously noted.

- Poleward of $10^{\circ} \mathrm{S}$, however, the LLICs and LLSCs are not distinguishable from our analyses and the available data. As the multiple LLSCs get deeper and denser, they are observed at $1000 \mathrm{~m}$ and are present in the density layer defined for the LLICs.

For an alternative view of the horizontal structure of the subthermocline and intermediate circulation systems, we look at the zonal velocity and the potential vorticity contours inferred from the Argo velocity product on three potential density levels (Fig. 11): at the top of the primary SCCs $\left(26.4 \mathrm{~kg} \mathrm{~m}^{-3}\right)$; at their base, which is also in the core of the higher-latitude LLSCs $\left(26.9 \mathrm{~kg} \mathrm{~m}^{-3}\right)$; and in the core of the LLICs, near $1000 \mathrm{~m}\left(27.4 \mathrm{~kg} \mathrm{~m}^{-3}\right)$. Because the density of the LLSC cores changes from west to east and poleward, it is not possible to pick an isopycnal corresponding to them in the whole tropical
Pacific. On the $26.4 \mathrm{~kg} \mathrm{~m}^{-3}$ isopycnal, zonal jets follow lines of constant PV, which diverge poleward from west to east in the central and eastern parts of the basin, east of about $160^{\circ} \mathrm{W}$. West of this longitude, zonal currents and PV contours are almost zonal. The first and secondary eastward SCCs coincide with PV fronts, surrounding a pool of very low PV on their equatorward sides (see also Rowe et al. 2000). On the $27.4 \mathrm{~kg} \mathrm{~m}^{-3}$ isopycnal, the PV isolines are almost zonal, and the zonal jets do not diverge from the equator. In between, on $26.9 \mathrm{~kg} \mathrm{~m}^{-3}$, the situation is less clear. The secondary and third southern SCCs also coincide with PV fronts, and pools of homogeneous PV are also observed.

On the 26.9 and $27.4 \mathrm{~kg} \mathrm{~m}^{-3}$ isopycnals, eastward and westward currents of similar amplitude alternate in latitude, suggesting that we are looking at zonally elongated recirculation cells rather than independent zonal currents (Rowe et al. 2000; Stramma et al. 2010). Such recirculation cells also appear on the shallower $26.4 \mathrm{~kg} \mathrm{~m}^{-3}$ isopycnal in the southwest Pacific, but 


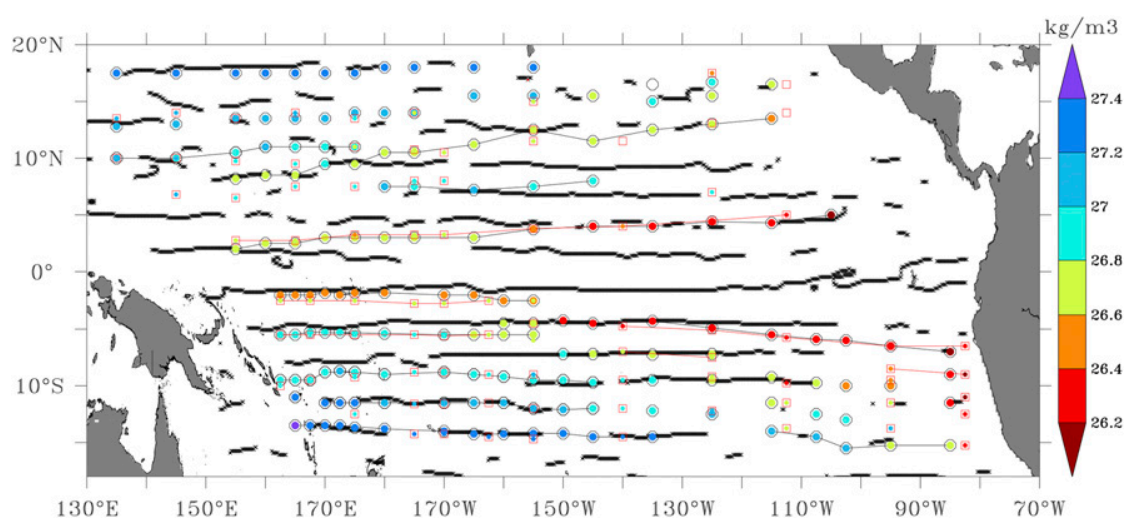

FIG. 10. Thick black lines indicate the positions of the eastward maxima in zonal velocity for the LLICs in the sigma 27.2-27.65 layer (from about 730 to $1850 \mathrm{~m}$ ). Superimposed are the positions of the eastward maxima in zonal velocity from the LLSCs derived from the mean zonal velocity patterns averaged in longitudinal boxes. Circles in black denote the locations of the jet cores inferred from Argo velocity product; squares in red are from SADCP data; and thin black and red lines link the circles and squares between longitudes when jets are clearly connected. Colors inside the circles and squares give the density of the velocity core $\left(\mathrm{kg} \mathrm{m}^{-3}\right)$.

eastward currents clearly dominate the westward currents near the equator at this depth. Velocity fields are also noisier in the Northern Hemisphere, where it is difficult to identify jets and to follow them, for the LLICs as well as for the multiple LLSCs. They are stronger, better defined, and identified in the Southern Hemisphere.

\section{b. First and secondary SCCs}

There is a striking discontinuity in the Southern Hemisphere first and secondary SCCs near $155^{\circ} \mathrm{W}$, with no obvious explanation (Figs. 10,11). This discontinuity also clearly appears when examining the Ka'imimoana SADCP repeated lines along $170^{\circ}, 155^{\circ}$, and $140^{\circ} \mathrm{W}$ (Fig. 12). At $170^{\circ} \mathrm{W}$, the first SCC is located broadly at $2.5^{\circ} \mathrm{S}$, still appearing as a leg of the EUC, and the secondary SCC is located at $5.5^{\circ} \mathrm{S}$. At $155^{\circ} \mathrm{W}$, there is only one SCC at $4.5^{\circ} \mathrm{S}$, and it is not clear if this jet originates from one or the other, if it is a mix of both zonal currents, or if the zonal jets from either side of $160^{\circ} \mathrm{W}$ are disconnected. At $140^{\circ} \mathrm{W}$, the eastward current located at $4.5^{\circ} \mathrm{S}$ is clearly distinct from the EUC. The fact that this discontinuity is seen in two independent datasets between longitudes well sampled by repeated cruises precludes - or at least reduces-the possibility that it might arise from inadequate sampling of variability. There is no major topographic barrier in the Southern Hemisphere at these longitudes; most of the Line Islands topography is north of the equator, with little more than the tiny and isolated Jarvis and Malden Islands in the south. The shift in the SSCs coincides, however, with major changes in the depths of isopycnals and, correspondingly, in the paths of PV contours. There is a rapid deepening with longitude of the 26.5 and $26.6 \mathrm{~kg} \mathrm{~m}^{-3}$ isopycnals between $165^{\circ}$ and $150^{\circ} \mathrm{W}$, corresponding roughly to the base of the thermostad waters (e.g., Johnson and McPhaden 1999; Qu et al. 2009) and an abrupt decrease in PV (increase in thermostad thickness) from west to east of $155^{\circ} \mathrm{W}$ (Fig. 11, upper panel), with a corresponding southward shift of the first southern SCC. This deepening has been noted and discussed in previous studies (e.g., Johnson and McPhaden 1999; Rowe et al.2000), but the transition zone was not as well resolved. The SCC appears to be splitting at the kink in the PV contour on the $26.4 \mathrm{~kg} \mathrm{~m}^{-3}$ isopycnal (Fig. 11, top panel), with part of its transport continuing straight to the east into the low-PV thermostad, while the remainder follows the PV contour, ending up well to the south of its original latitude. There is a suggestion of a less extreme kink in the Northern Hemisphere PV contours on the $26.4 \mathrm{~kg} \mathrm{~m}^{-3}$ isopycnal, with the northern SCC transport similarly splitting into a branch heading east into the thermostad while the larger fraction of the transport follows the PV contours as they shift poleward.

\section{Discussion}

Based on two independent velocity estimates, inferred from SADCP and Argo data, our study described the 3D structure of the mean zonal circulation in the tropical Pacific Ocean from the thermocline to deeper than $1000 \mathrm{~m}$. The innovations brought by this paper are the high horizontal resolution of the analysis, the vertical extent to 1000- or 2000-m depth, and the basin-scale view from $18^{\circ} \mathrm{S}$ to $18^{\circ} \mathrm{N}$. This was made possible by the 

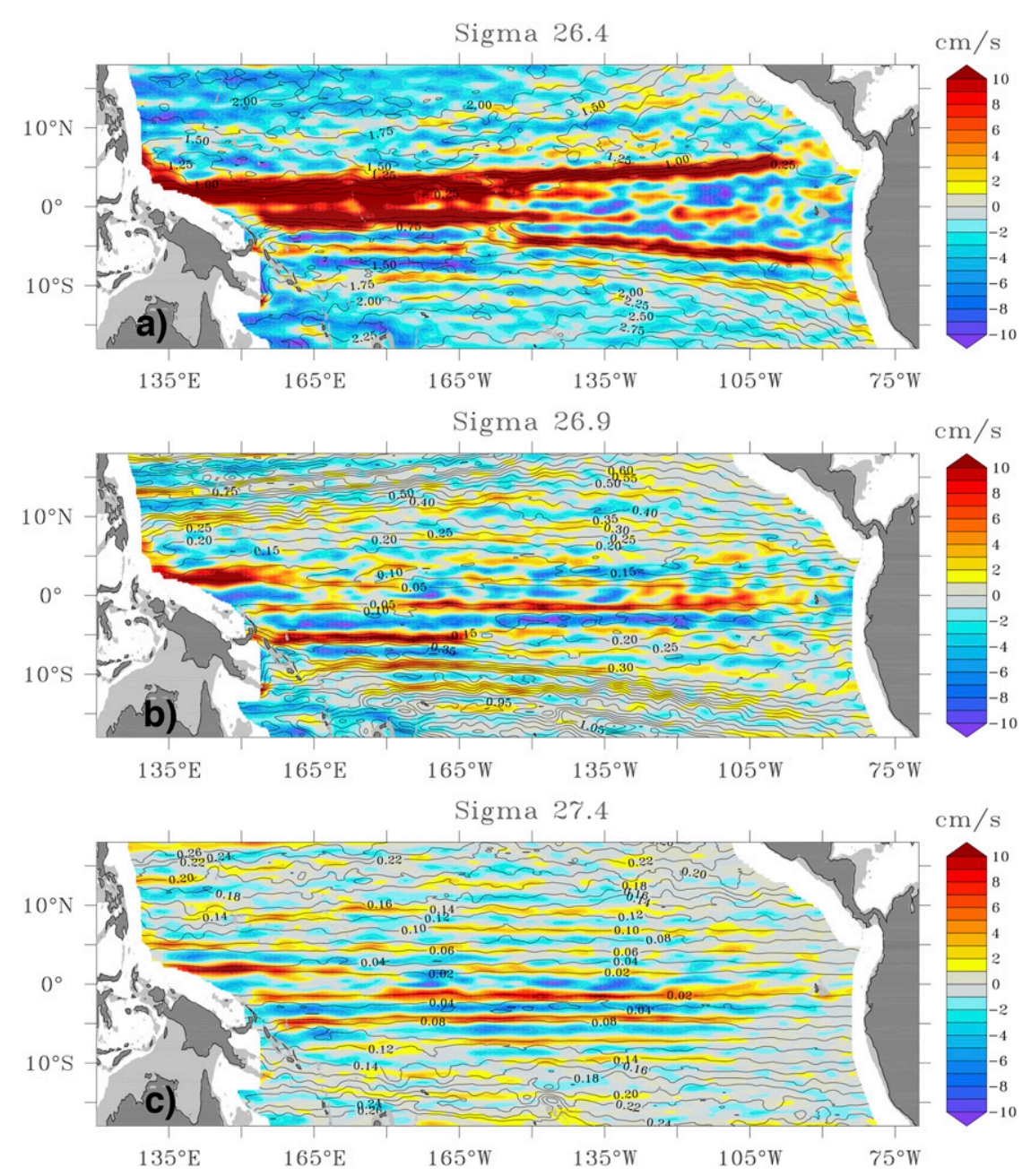

FIG. 11. Zonal currents ( $\mathrm{cm} \mathrm{s}^{-1}$, colors) from Argo velocity product and absolute value of potential vorticity $\left(10^{-10} \mathrm{~m}^{-1} \mathrm{~s}^{-1}\right.$, black contours) gridded on the (a) $26.4 \mathrm{~kg} \mathrm{~m}^{-3}$ (between 110 and $450 \mathrm{~m}$ ), (b) $26.9 \mathrm{~kg} \mathrm{~m}^{-3}$ (between 400- and 600-m depth), and (c) $27.4 \mathrm{~kg} \mathrm{~m}^{-3}$ (about 1050-m depth) potential density surfaces.

extensive Argo dataset that is now able to resolve the narrow geostrophic zonal currents below the thermocline even very close to the equator and to the new generation of SADCP instruments that gives access to currents down to $800-$ or $1200-\mathrm{m}$ depth.

This study highlights the existence of two apparently distinct systems of alternating zonal jets below the thermocline in a large equatorial band of latitudes $\left(10^{\circ} \mathrm{S}-10^{\circ} \mathrm{N}\right)$ :

- A series of alternating subthermocline zonal jets (the LLSCs) beneath the thermocline, with their cores deepening and becoming denser poleward from the equator. These subthermocline jets extend from about 200 to $800 \mathrm{~m}$ and tend to diverge poleward and to shoal to lighter densities from west to east. This system includes the well-known, westward-flowing EIC at the equator, flanked by the primary eastward-flowing Tsuchiya jets and with a secondary SCC in the Southern Hemisphere. There is an abrupt change in latitude of the southern Tsuchiya jet near $155^{\circ} \mathrm{W}$.

- A series of alternating intermediate zonal jets (the LLICs) extending from about 700 to at least $2000 \mathrm{~m}$. Using a reference at $1000 \mathrm{~m}$ to Argo drift velocities is crucial to capture these structures. These zonal jets tend to converge slightly equatorward from west to east. The L-EIC, NICC, SICC, NEIC, and SEIC are the nearequatorial parts of this system of intermediate currents.

From $10^{\circ} \mathrm{S}$ to $10^{\circ} \mathrm{N}$, jets cores from the two systems are clearly distinct, especially in the central Pacific, suggesting that they have different forcing mechanisms. These subthermocline and intermediate circulations involve both eastward and westward currents of similar 

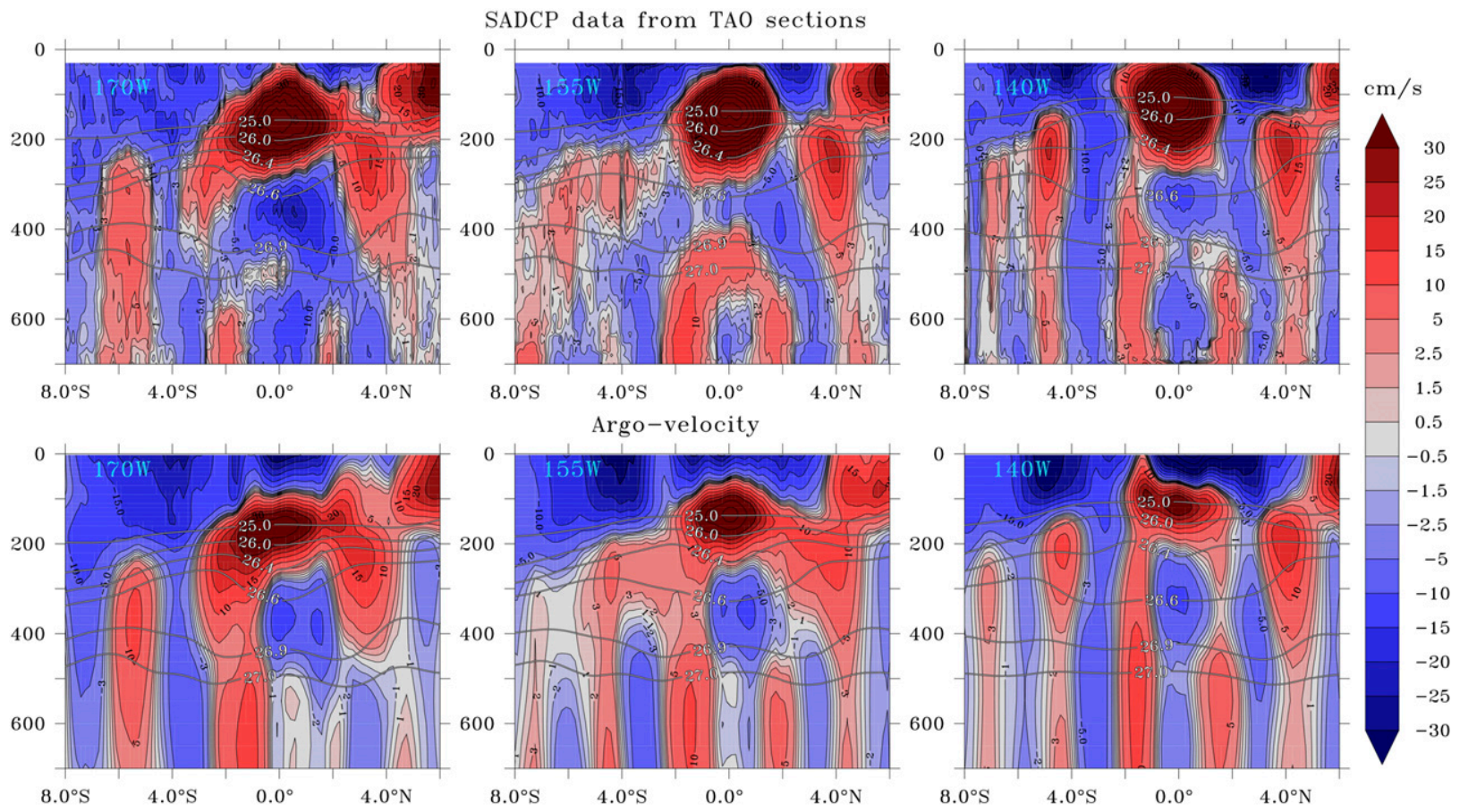

FIG. 12. Mean zonal velocity from (top) SADCP data and (bottom) Argo velocity product at (left) $170^{\circ} \mathrm{W}$, (center) $155^{\circ} \mathrm{W}$, and (right) $140^{\circ} \mathrm{W}$ in $\mathrm{cm} \mathrm{s}^{-1}$. Superimposed are some selected isopycnals.

amplitude, suggestive of horizontal recirculations. Poleward of $10^{\circ}$, however, the multiple subthermocline jets get denser and deeper, extending below $1000 \mathrm{~m}$, and are no longer distinguishable from the intermediate zonal jets. This suggests that the two systems of jets merge poleward of that latitude or that we observe a third system of jets. Qiu et al. (2013a) refer to these jets as NEUC jets in the Northern Hemisphere. Both systems of jets are stronger near the equator and in the Southern Hemisphere and weaker and noisier in the Northern Hemisphere.

In the tropics and near the equator, a theory to explain these systems of jets as a whole is still lacking. At present, the available theories address the formation of only specific parts of these systems of jets, focusing either on the near-equatorial circulation (Tsuchiya jets, deep jets at the equator and intermediate currents between $3^{\circ} \mathrm{S}$ and $3^{\circ} \mathrm{N}$ ) or on extraequatorial intermediate currents (poleward of $\sim 9^{\circ} \mathrm{N}$ ). These theories are briefly presented; the purpose is not to describe them comprehensively but to discuss them in the light of our new results. For each of our findings listed above, how do the existing theories relate to the observations?

\section{a. A series of alternating subthermocline zonal jets: The LLSCS}

Four key ingredients have been proposed to explain the creation and properties of the Tsuchiya jets (primary SCCs): the upwelling regions in the east (McCreary et al. 2002; Furue et al. 2007, 2009), the equatorward shoaling of the thermocline (Marin et al. 2000; Hua et al. 2003; Marin et al. 2003), the tropical instability waves (Jochum and Malanotte-Rizzoli 2004; Ishida et al. 2005), and the zonal slope of the thermocline (Johnson and Moore 1997). From both analytic and numerical layered models of the tropical Pacific, McCreary et al. (2002) suggest that the Tsuchiya jets are mostly driven by upwelling along the South America coast and in the Costa Rica Dome below the intertropical convergence zone (ITCZ). The Tsuchiya jets appear as geostrophic currents along arrested fronts generated by the convergence or intersection of the characteristics of the Rossby waves carrying information about the density structure away from the upwelling regions. These results have been further supported in global and regional OGCMs forced by idealized winds (Furue et al. 2007, 2009). Marin et al. (2000) propose a mechanism similar to the atmospheric Hadley cells to explain the Tsuchiya jets. In response to the large-scale equatorial shoaling of the ventilated thermocline, meridional ageostrophic and diapycnal cells are created and redistribute angular momentum, creating eastward jets analogous to the atmospheric jet streams. Alternatively, in a numerical simulation of the tropical Atlantic, Jochum and Malanotte-Rizzoli (2004) show that the southern Tsuchiya jet is maintained 
against dissipation by the convergence of the EliassenPalm flux associated with the tropical instability wave (TIW). A similar mechanism was found in the tropical Pacific by Ishida et al. (2005), where high mesoscale eddy activity is shown to accelerate the SCC (especially for the northern Tsuchiya jet in the eastern part of basin) and to generate a large region of PV homogenization in which strong horizontal recirculations take place.

Our observations reveal that the Tsuchiya jets, discussed as individual objects in the literature, are part of a large meridional-scale system of eastward and westward jets, which we call LLSCs. These multiple eastward jets are not predicted by the theories involving oceanic Hadley cells (Marin et al. 2000) or TIWs (Jochum and Malanotte-Rizzoli 2004). One hypothesis is that the multiple southern LLSCs might be related to upwelling along South America; Ishida et al. (2005) indicates that the secondary southern SCC could be related to a secondary region of upwelling along the South American coast. The multiple LLSCs may be related to other upwelling cells in the Chile upwelling region, which would explain why the LLSCs are stronger in the Southern Hemisphere. This hypothesis warrants investigation that is beyond the scope of this study. Other hypotheses to explain the hemispheric asymmetry include asymmetry in the basin shape, asymmetry in the wind forcing, asymmetry in the upper-ocean currents and variability, and asymmetry in the PV structure. Note that none of the above theories explain the presence of westward jets.

\section{b. Abrupt split and change in latitude of the southern Tsuchiya jet near $155^{\circ} \mathrm{W}$}

This change has not been previously documented to our knowledge. Our observations also show that the multiple LLSCs tend to diverge poleward only east of this longitude. Given a prescribed eastward shoaling of the thermocline, the inertial jet model by Johnson and Moore (1997) demonstrates that a prescribed PV-conserving eastward jet below the thermocline must shift poleward and accelerate from west to east. The zonal slope of the thermocline is also crucial for the mechanism of arrested fronts proposed by McCreary et al. (2002), since it contributes to the convergence of the Rossby wave characteristics extending westward from the upwelling regions. Their model also inherently directs the SCCs along PV contours. The thermocline is flat in the western Pacific, beginning to shoal only in the central/eastern Pacific, so our observations are generally consistent with the PV-conserving aspect of these theories. To our knowledge none of the theories, however, accounts for the abrupt change in thermostad thickness and Southern Hemisphere Tsuchiya jet path near $155^{\circ} \mathrm{W}$.

\section{c. A series of alternating intermediate zonal jets: The LLICs}

Our observations also confirm that the L-EIC, NICC, SICC, NEIC, and SEIC are embedded in a broader system of zonal jets, extending to at least $10^{\circ} \mathrm{N} / \mathrm{S}$; these zonal jets cannot be considered as a purely equatorially trapped phenomenon. Theories to explain the intermediate circulation near the equator mainly rely on intraseasonal variability below the thermocline; this deep intraseasonal variability can be forced by the instability of deep western boundary currents (Hua et al. 2008; Ménesguen et al. 2009) or forced at the surface by the instability of upper-ocean currents (Ascani et al. 2010). The key mechanisms are the destabilization or the dissipation of equatorial mixed Rossby-gravity waves that rectify into mean zonal flow [d'Orgeville et al. 2007; Hua et al. 2008; Ménesguen et al. 2009; Ascani et al. 2010; see Ascani et al. (2015) for a review]. Given the equatorially trapped nature of baroclinic mixed Rossby gravity waves, mostly confined to $5^{\circ} \mathrm{S}-5^{\circ} \mathrm{N}$, the destabilization of these waves cannot explain the presence of alternating intermediate zonal jets beyond $5^{\circ}$ in latitude [as discussed in Ascani et al. (2015)]. Perhaps the instability of other types of waves explains the extension of the observed deep equatorial intermediate circulation to at least $10^{\circ}$. Farrar (2011) showed the presence of intraseasonal barotropic Rossby waves radiating from the tropical instability waves to $20^{\circ} \mathrm{N}$, and Gill (1974) demonstrated that midlatitude barotropic Rossby waves are unstable and may favor the creation of zonal jets. Alternatively, the instability of an annual first-baroclinicmode Rossby wave is invoked by Qiu et al. (2013b) to explain the zonal flows poleward of $10^{\circ} \mathrm{N}$.

\section{d. Recirculations}

Tsuchiya jets are often considered as eastward jets embedded in the deep extensions of the broad westward South and North Equatorial Currents. Our observations show that in the western Pacific, eastward currents clearly dominate the westward currents near the equator on the $26.4 \mathrm{~kg} \mathrm{~m}^{-3}$ isopycnal (Fig. 11) but also suggest partial recirculations, as already noted (Rowe et al. 2000). Farther east or poleward, however, our observations show a spatial correspondence between the amplitude of westward and eastward currents for the LLSCs, suggesting stronger horizontal recirculations associated with the jets. This would contrast with the description of purely free-flowing inertial jets forced at the western or eastern boundaries, as in Johnson and Moore (1997) or McCreary et al. (2002). 
From $10^{\circ} \mathrm{S}$ to $10^{\circ} \mathrm{N}$, jets cores from the two systems are clearly distinct, suggesting that they have different forcing mechanisms. This is not surprising given the key hypotheses used for the existing theories. All the mechanisms for the Tsuchiya jets listed above (except the tropical instability waves) are not relevant for the intermediate currents, since (i) the isopycnals are mostly flat at basin scale below $1000 \mathrm{~m}$ in our region of interest and (ii) the isopycnals are too deep to be directly connected with the upwelling regions. On the contrary, theories explaining near-equatorial intermediate zonal currents are derived for a uniform stratification; their extension to the case of the Tsuchiya jets where the thermocline is seen to shoal both equatorward and eastward remains to be tested. Theories proposed to explain the Tsuchiya jets (requiring a spatially variable stratification, observed above $800 \mathrm{~m}$ ) may thus coexist with theories explaining the intermediate currents (applicable to uniform stratification, observed deeper).

Poleward of $10^{\circ}$, however, the multiple LLSCs are no longer distinguishable from the LLICs. This suggests that the two systems of jets merge poleward of that latitude or that a different system of currents (and different mechanism) should be considered. Qiu et al. (2013b) studied the mechanism of the subthermocline jets in the Northern Hemisphere both theoretically and in numerical models. They found that the subthermocline jets result from two successive processes: (i) the generation of mesoscale eddies through the instability, by wave-triad interactions, of wind-forced, annual, first-baroclinic-mode Rossby waves in the eastern Pacific and (ii) the formation of zonal jets through the convergence of PV fluxes associated with the eddies. The jets thus appear in this framework as latent jets [following the terminology proposed by Berloff et al. (2011)], that is, as weak jets relative to ambient eddies, and long-term time averages would be needed to isolate them.

In contrast, following Kessler and Gourdeau (2006), Taguchi et al. (2012) propose that the eastward intermediate jets detected in the southern tropical ocean are partly forced by coupled ocean-atmosphere processes. In their coupled general circulation model, the zonal jets have a signature in zonal currents at the surface, inducing sea surface temperature anomalies at the same spatial scales through zonal advection. These SST anomalies impact the atmosphere, creating small-scale wind stress curls collocated with the temperature anomalies, which reinforce the zonal jets in accordance with Sverdrup balance. We applied the same meridional filter in our data, but unlike Taguchi et al. (2012), we did not find any surface current signature. As shown in Fig. 5, we explain the difference by our use of Argo drifts to reference the geostrophic shears versus the zero reference at $2000 \mathrm{~m}$ in Taguchi et al. (2012). Moreover, the lower resolution $\left(1^{\circ}\right)$ of their gridded velocity product may explain part of the difference. In the Northern Hemisphere, Qiu et al. (2013a) also failed to find small-scale wind stress curl features collocated with the NEUC jets.

\section{Conclusions}

Our knowledge of the near-equatorial currents is still far from being comprehensive. Our observations show how individual elements often considered as independent features (primary and secondary Tsuchiya jets, LEIC, SICC, NICC, SEIC, NEIC, etc.), are embedded in a broader meridional system of basin-scale zonal currents. They also emphasize that the multiple LLSCs are distinct from the intermediate currents, at least in the $10^{\circ} \mathrm{S}-10^{\circ} \mathrm{N}$ band. Theories focusing on the formation of individual elements of this subthermocline equatorial circulation should be revisited or completed to account for the observed broader meridional extension of the zonal current systems. It is possible that one or more new theoretical frameworks will be required to explain the system as a whole. A successful model will need to account for the similarities in the structures between the Northern and Southern Hemispheres-the regular alternation of eastward and westward flows-and the differences, with the Southern Hemisphere currents tending to be stronger and more regular than their Northern Hemisphere counterparts. It will also need to explain the large-scale pattern of current cores becoming denser with increasing latitude and becoming less dense from west to east, plus the abrupt shift in SCC and thermostad structure near $155^{\circ} \mathrm{W}$.

Some of the jets in the LLSC and LLIC systems may be latent-appearing only as weak Eulerian mean flows in a stronger eddy field, perhaps responsible for little or no Lagrangian transport-but some play an important role in the redistribution of water properties across the Pacific Ocean. The SCCs have been shown to transport $13^{\circ} \mathrm{C}$ water to the eastern Pacific (Tsuchiya 1981) to feed the oxygen minimum zone in the eastern Pacific (Stramma et al. 2010) and to be crucial for a good representation of the nutrients and oxygen in the deep eastern Pacific Ocean in coupled biogeochemical models (Dietze and Loeptien 2013). Their signature in oxygen or nutrients' properties is thus worth investigating in more detail, to understand their role in the redistribution of mass and water properties across the basin. The role of other jets in basin-scale transport of water properties remains an open question.

This study highlighted the complexity of the mean zonal velocity structures observed in the tropical Pacific 
Ocean. We still lack a comprehensive theoretical understanding of why these jets systems exist. Despite the recent expansion in observing systems, our ability to measure or deduce subsurface oceanic currents is still very limited. The density of the Argo array is sufficient to give a mean view of the currents, with some aspects of their seasonal or interannual variability (Brandt et al. 2011; Cravatte et al. 2012), but not to show their variability on the full range of time scales of interest-and possibly of dynamical relevance to the mean structure. Cruises and ship transects give only snapshots of these highly variable currents. Despite an impressive dataset, with more than 190 cruises, mean velocity fields inferred from SADCP data are still noisy. Filling in our descriptive picture and our theoretical understanding of the tropical subthermocline circulation system, and its variability on scales from days to decades, remains a daunting challenge.

Acknowledgments. This study has been possible thanks to the effort of many scientists, engineers, and crew who carefully recorded, processed, and made available SADCP data. The authors are very grateful to all who contributed. SADCP data were downloaded freely from various databases. Many of them come from the Joint Archive for Shipboard ADCP (JASADCP; http://ilikai.soest.hawaii.edu/sadcp/main_inv.html). We greatly thank J. Hummon and P. Caldwell for maintaining this very useful resource. Other SADCP data come from CSIRO (http://www.marine.csiro.au/maru/ marlin_admin.survey_list), from IFREMER, and from JAMSTEC. We thank R. Czeschel and J. Murray for providing SADCP data from the M90 and EUC-Fe cruise. We also thank S. Chen and B. Qiu for providing processed SADCP data along the $137^{\circ} \mathrm{S}$ section and Dr. T. Nakano and the Japan Meteorological Agency for making them available.

This study has also been possible thanks to the amount of Argo data, collected and made freely available by the International Argo Program and the national programs that contribute to it (http://www.argo.ucsd.edu; http:// argo.jcommops.org). The Argo Program is part of the Global Ocean Observing System (Argo 2000). The authors also thank the Scripps for making available their gridded Argo product and M. Ollitrault and J.-P. Ranou for making the ANDRO Atlas available (10.17882/ 47077). They also wish to thank W. S. Kessler, G. Johnson, and C. Menesguen for helpful discussions on this work and two anonymous reviewers for their comments, which helped to improve the manuscript.

The authors finally wish to acknowledge the use of the Ferret program for analysis and graphics in this paper. Ferret is a product of NOAA's Pacific Marine Envi- ronmental Laboratory. (Information is available online at http://ferret.pmel.noaa.gov/Ferret.) S. Cravatte, E. Kestenare, and F. Marin were funded by IRD. E. Firing and P. Dutrieux were supported by the NSF through Grant OCE05-50857. This work was supported by the French national programme LEFE/INSU, within the project ZEBRE.

\section{REFERENCES}

Argo, 2000: Argo float data and metadata from Global Data Assembly Centre (Argo GDAC). Sea Scientific Open Data Edition, doi:10.17882/42182.

Ascani, F., E. Firing, P. Dutrieux, J. McCreary, and A. Ishida, 2010: Deep equatorial ocean circulation induced by a forceddissipated Yanai beam. J. Phys. Oceanogr., 40, 1118-1142, doi:10.1175/2010JPO4356.1.

,-- , J. P. McCreary, P. Brandt, and R. J. Greatbatch, 2015: The deep equatorial ocean circulation in wind-forced numerical solutions. J. Phys. Oceanogr., 45, 1709-1734, doi:10.1175/JPO-D-14-0171.1.

Berloff, P., S. Karabasov, J. T. Farrar, and I. Kamenkovich, 2011: On latency of multiple zonal jets in the oceans. J. Fluid Mech., 686, 534-567, doi:10.1017/jfm.2011.345.

Brandt, P., A. Funk, V. Hormann, M. Dengler, R. J. Greatbatch, and J. M. Toole, 2011: Interannual atmospheric variability forced by the deep equatorial Atlantic Ocean. Nature, 473, 497-501, doi:10.1038/nature10013.

Cravatte, S., G. Madec, T. Izumo, C. Menkes, and A. Bozec, 2007: Progress in the 3-D circulation of the eastern equatorial Pacific in a climate ocean model. Ocean Modell., 17, 28-48, doi:10.1016/j.ocemod.2006.11.003.

_ W. S. Kessler, and F. Marin, 2012: Intermediate zonal jets in the tropical Pacific Ocean observed by Argo floats. J. Phys. Oceanogr., 42, 1475-1485, doi:10.1175/JPO-D-11-0206.1.

— E. Kestenare, G. Eldin, A. Ganachaud, J. Lefevre, F. Marin, C. Menkes, and J. Aucan, 2015: Regional circulation around New Caledonia from two decades of observations. J. Mar. Syst., 148, 249-271, doi:10.1016/j.jmarsys.2015.03.004.

Czeschel, R., L. Stramma, F. U. Schwarzkopf, B. S. Giese, A. Funk, and J. Karstensen, 2011: Middepth circulation of the eastern tropical South Pacific and its link to the oxygen minimum zone. J. Geophys. Res., 116, C01015, doi:10.1029/ 2010JC006565.

,,-- R. A. Weller, and T. Fischer, 2015: Circulation, eddies, oxygen, and nutrient changes in the eastern tropical South Pacific Ocean. Ocean Sci., 11, 455-470, doi:10.5194/os-11-455-2015.

Davis, R. E., 2005: Intermediate-depth circulation of the Indian and South Pacific Oceans measured by autonomous floats. J. Phys. Oceanogr., 35, 683-707, doi:10.1175/JPO2702.1.

Dietze, H., and U. Loeptien, 2013: Revisiting "nutrient trapping" in global coupled biogeochemical ocean circulation models. Global Biogeochem. Cycles, 27, 265-284, doi:10.1002/ gbc.20029.

d'Orgeville, M., B. L. Hua, and H. Sasaki, 2007: Equatorial deep jets triggered by a large vertical scale variability within the western boundary layer. J. Mar. Res., 65, 1-25, doi:10.1357/ 002224007780388720.

Dutrieux, P., 2009: Tropical western Pacific currents and the origin of intraseasonal variability below the thermocline. Ph.D. thesis, University of Hawai'i at Mānoa, 122 pp. 
Eriksen, C. C., 1981: Deep currents and their interpretation as equatorial waves in the western Pacific Ocean. J. Phys. Oceanogr., 11, 48-70, doi:10.1175/1520-0485(1981)011<0048:DCATIA >2.0.CO;2.

Farrar, J. T., 2011: Barotropic Rossby waves radiating from tropical instability waves in the Pacific Ocean. J. Phys. Oceanogr., 41, 1160-1181, doi:10.1175/2011JPO4547.1.

Firing, E., 1987: Deep zonal currents in the central equatorial Pacific. J. Mar. Res., 45, 791-812, doi:10.1357/ 002224087788327163.

—, S. E. Wijffels, and P. Hacker, 1998: Equatorial subthermocline currents across the Pacific. J. Geophys. Res., 103, 21 413-21 423, https://doi.org/10.1029/98JC01944.

Furue, R., J. P. McCreary, Z. Yu, and D. Wang, 2007: Dynamics of the southern Tsuchiya jet. J. Phys. Oceanogr., 37, 531-553, doi:10.1175/JPO3024.1.

,-- , and — 2009: Dynamics of the northern Tsuchiya jet. J. Phys. Oceanogr., 39, 2024-2051, doi:10.1175/2009JPO4065.1.

Gill, A. E., 1974: The stability of planetary waves on an infinite beta-plane. Geophys. Fluid Dyn., 6, 29-47, doi:10.1080/ 03091927409365786

Gouriou, Y., and J. Toole, 1993: Mean circulation of the upper layers of the western equatorial Pacific Ocean. J. Geophys. Res., 98, 22 495-22 520, https://doi.org/10.1029/93JC02513.

_, T. Delcroix, and G. Eldin, 2006: Upper and intermediate circulation in the western equatorial Pacific Ocean in October 1999 and April 2000. Geophys. Res. Lett., 33, L10603, doi:10.1029/2006GL025941.

Hua, B. L., F. Marin, and R. Schopp, 2003: Three-dimensional dynamics of the subsurface countercurrents and equatorial thermostad. Part I: Formulation of the problem and generic properties. J. Phys. Oceanogr., 33, 2588-2609, doi:10.1175/ 1520-0485(2003)033<2588:TDOTSC $>2.0$.CO;2.

—, M. d'Orgeville, M. D. Fruman, C. Menesguen, R. Schopp, P. Klein, and H. Sasaki, 2008: Destabilization of mixed Rossby gravity waves and the formation of equatorial zonal jets. J. Fluid Mech., 610, 311-341, doi:10.1017/S0022112008002656.

Ishida, A., H. Mitsudera, Y. Kashino, and T. Kadokura, 2005: Equatorial Pacific Subsurface Countercurrents in a highresolution global ocean circulation model. J. Geophys. Res., 110, C07014, doi:10.1029/2003JC002210.

Jochum, M., and P. Malanotte-Rizzoli, 2004: A new theory for the generation of the equatorial subsurface countercurrents. J. Phys. Oceanogr., 34, 755-771, doi:10.1175/1520-0485(2004)034<0755 ANTFTG $>2.0 . \mathrm{CO} ; 2$

Johnson, G. C., and D. W. Moore, 1997: The Pacific Subsurface Countercurrents and an inertial model. J. Phys. Oceanogr., 27, 2448-2459, doi:10.1175/1520-0485(1997)027<2448: TPSCAA $>2.0 . \mathrm{CO} ; 2$

- , and M. J. McPhaden, 1999: Interior pycnocline flow from the subtropical to the equatorial Pacific Ocean. J. Phys. Oceanogr., 29, 3073-3089, doi:10.1175/1520-0485(1999)029<3073 IPFFTS $>2.0 . \mathrm{CO} ; 2$

_ B. M. Sloyan, W. S. Kessler, and K. E. McTaggart, 2002a: Direct measurements of upper ocean currents and water properties across the tropical Pacific during the 1990s. Prog. Oceanogr., 52, 31-61, doi:10.1016/S0079-6611(02)00021-6.

—, E. Kunze, K. E. McTaggart, and D. W. Moore, 2002b: Temporal and spatial structure of the equatorial deep jets in the Pacific Ocean. J. Phys. Oceanogr., 32, 3396-3407, doi:10.1175/1520-0485(2002)032<3396:TASSOT >2.0.CO;2.

Kessler, W. S., and L. Gourdeau, 2006: Wind-driven zonal jets in the South Pacific Ocean. Geophys. Res. Lett., 33, L03608, doi:10.1029/2005GL025084.
— and S. Cravatte, 2013: Mean circulation of the Coral Sea. J. Geophys. Res. Oceans, 118, 6385-6410, doi:10.1002/ 2013 JC009117.

Marin, F., B. L. Hua, and S. Wacongne, 2000: The equatorial thermostad and subsurface countercurrents in the light of the dynamics of atmospheric Hadley cells. J. Mar. Res., 58, 405-437, doi:10.1357/002224000321511098.

__ , R. Schopp, and B. L. Hua, 2003: Three-dimensional dynamics of the subsurface countercurrents and equatorial thermostad. Part II: Influence of the large-scale ventilation and of equatorial winds. J. Phys. Oceanogr., 33, 2610-2626, doi:10.1175/1520-0485(2003)033<2610: TDOTSC $>2.0 . \mathrm{CO} ; 2$.

— , E. Kestenare, T. Delcroix, F. Durand, S. Cravatte, G. Eldin, and R. Bourdalle-Badie, 2010: Annual reversal of the equatorial intermediate current in the Pacific: Observations and model diagnostics. J. Phys. Oceanogr., 40, 915-933, doi:10.1175/2009JPO4318.1.

McCreary, J. P., P. Lu, and Z. Yu, 2002: Dynamics of the Pacific Subsurface Countercurrents. J. Phys. Oceanogr., 32, 2379-2404, doi:10.1175/1520-0485(2002)032<2379:DOTPSC $>2.0 . C O ; 2$.

Ménesguen, C., B. L. Hua, M. D. Fruman, and R. Schopp, 2009: Dynamics of the combined extra-equatorial and equatorial deep jets in the Atlantic. J. Mar. Res., 67, 323-346, doi:10.1357/ 002224009789954766

Montes, I., F. Colas, X. Capet, and W. Schneider, 2010: On the pathways of the equatorial subsurface currents in the eastern equatorial Pacific and their contributions to the Peru-Chile Undercurrent. J. Geophys. Res., 115, C09003, doi:10.1029/ 2009JC005710.

Nakano, T., I. Kaneko, M. Endoh, and M. Kamachi, 2005: Interannual and decadal variabilities of NPIW salinity minimum core observed along JMA's hydrographic repeat sections. J. Oceanogr., 61, 681-697, doi:10.1007/s10872-005-0076-5.

Ollitrault, M., and J.-P. Rannou, 2013: ANDRO: An Argo-based deep displacement dataset. J. Atmos. Oceanic Technol., 30, 759-788, doi:10.1175/JTECH-D-12-00073.1.

- and A. Colin de Verdière, 2014: The ocean general circulation near 1000-m depth. J. Phys. Oceanogr., 44, 384-409, doi:10.1175/JPO-D-13-030.1.

—, M. Lankhorst, D. Fratantoni, P. Richardson, and W. Zenk, 2006: Zonal intermediate currents in the equatorial Atlantic Ocean. Geophys. Res. Lett., 33, L05605, doi:10.1029/2005GL025368.

Park, J. J., K. Kim, B. A. King, and S. C. Riser, 2005: An advanced method to estimate deep currents from profiling floats. J. Atmos. Oceanic Technol., 22, 1294-1304, doi:10.1175/ JTECH1748.1.

Picaut, J., and R. Tournier, 1991: Monitoring the 1979-1985 equatorial Pacific Current transports with expendable bathythermograph data. J. Geophys. Res., 96, 3263-3277, doi:10.1029/ 90JC02066.

Ponte, R. M., and J. Luyten, 1989: Analysis and interpretation of deep equatorial currents in the central Pacific. J. Phys. Oceanogr., 19, 1025-1038, doi:10.1175/1520-0485(1989)019<1025: AAIODE $>2.0 . \mathrm{CO} ; 2$.

Qiu, B., D. L. Rudnick, S. Chen, and Y. Kashino, 2013a: Quasistationary North Equatorial Undercurrent jets across the tropical North Pacific Ocean. Geophys. Res. Lett., 40, 2183-2187, doi:10.1002/grl.50394.

S. Chen, and H. Sasaki, 2013b: Generation of the North Equatorial Undercurrent jets by triad baroclinic Rossby wave interactions. J. Phys. Oceanogr., 43, 2682-2698, doi:10.1175/ JPO-D-13-099.1. 
, T. Nakano, S. Chen, and P. Klein, 2017: Submesoscale transition from geostrophic flows to internal waves in the northwestern Pacific upper ocean. Nat. Commun., 8, 14055, doi:10.1038/ncomms14055.

Qu, T., S. Gao, I. Fukumori, R. A. Fine, and E. J. Lindstrom, 2009: Origin and pathway of equatorial $13^{\circ} \mathrm{C}$ water in the Pacific identified by a simulated passive tracer and its adjoint. J. Phys. Oceanogr., 39, 1836-1853, doi:10.1175/2009JPO4045.1.

Roemmich, D., and J. Gilson, 2009: The 2004-2008 mean and annual cycle of temperature, salinity, and steric height in the global ocean from the Argo Program. Prog. Oceanogr., 82, 81-100, doi:10.1016/j.pocean.2009.03.004.

Rosell-Fieschi, M., J. L. Pelegri, and J. Gourrion, 2015: Zonal jets in the equatorial Atlantic Ocean. Prog. Oceanogr., 130, 1-18, doi:10.1016/j.pocean.2014.08.008.

Rowe, G., E. Firing, and G. Johnson, 2000: Pacific Equatorial Subsurface Countercurrent velocity, transport, and potential vorticity. J. Phys. Oceanogr., 30, 1172-1187, doi:10.1175/ 1520-0485(2000)030<1172:PESCVT>2.0.CO;2.

Slemons, L. O., J. W. Murray, J. Resing, B. Paul, and P. Dutrieux, 2010: Western Pacific coastal sources of iron, manganese, and aluminum to the Equatorial Undercurrent. Global Biogeochem. Cycles, 24, GB3024, doi:10.1029/ 2009 GB003693.

Stramma, L., G. C. Johnson, E. Firing, and S. Schmidtko, 2010: Eastern Pacific oxygen minimum zones: Supply paths and multidecadal changes. J. Geophys. Res., 115, C09011, doi:10.1029/2009JC005976.

Taguchi, B., R. Furue, N. Komori, A. Kuwano-Yoshida, M. Nonaka, H. Sasaki, and W. Ohfuchi, 2012: Deep oceanic zonal jets constrained by fine-scale wind stress curls in the South Pacific Ocean: A high-resolution coupled GCM study. Geophys. Res. Lett., 39, L08602, doi:10.1029/2012GL051248.

Tsuchiya, M., 1975: Subsurface countercurrents in the eastern equatorial Pacific Ocean. J. Mar. Res., 33, 145-175.

- 1981: The origin of the Pacific equatorial $13^{\circ} \mathrm{C}$ water. J. Phys. Oceanogr., 11, 794-812, doi:10.1175/1520-0485(1981)011<0794: TOOTPE $>2.0 . \mathrm{CO} ; 2$.

van Sebille, E., I. Kamenkovich, and J. K. Willis, 2011: Quasi-zonal jets in 3-D Argo data of the northeast Atlantic. Geophys. Res. Lett., 38, L02606, doi:10.1029/2010GL046267.

Willis, J. K., and L.-L. Fu, 2008: Combining altimeter and subsurface float data to estimate the time-averaged circulation in the upper ocean. J. Geophys. Res., 113, C12017, doi:10.1029/ 2007JC004690.

Wyrtki, K., and B. Kilonsky, 1984: Mean water and current structure during the Hawaii-to-Tahiti Shuttle Experiment. J. Phys. Oceanogr., 14, 242-254, doi:10.1175/1520-0485(1984)014<0242: MWACSD $>2.0 . C O ; 2$.

Youngs, M. K., and G. C. Johnson, 2015: Basin-wavelength equatorial deep jet signals across three oceans. J. Phys. Oceanogr., 45, 2134-2148, doi:10.1175/JPO-D-14-0181.1. 